\title{
Avaliação pós-ocupação da qualidade na habitação por meio do aplicativo "Como você mora?": estudo de caso na cidade de Uberlândia
}

Housing quality post-occupancy evaluation through the "How do you live?" app: case study in the city of Uberlândia

\section{Simone Barbosa Villa \\ Dominique Cunha Bruno \\ Ana Luísa Trevisan dos Santos}

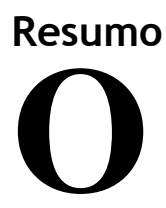

presente artigo tem como objetivo apresentar parte da pesquisa “COMO VOCÊ MORA: Sistema Interativo de Avaliação PósOcupação da Qualidade do Habitar em Meios Digitais”, expondo um estudo de caso a partir da avaliação pós-ocupação realizada por meio de um aplicativo. A pesquisa em questão representa um projeto de inovação tecnológica realizado através da parceria entre a Faculdade de Computação e a Faculdade de Arquitetura e Urbanismo e Design, da Universidade Federal de Uberlândia, cujos resultados principais incluem o desenvolvimento de aplicativo/questionário interativo intitulado "Como Você Mora”, conectado a um banco de dados de gerenciamento de avaliações pós-ocupacionais (APOs), denominado "Sistema APO Digital". O artigo pretende utilizar-se de um dos testes de validação do aplicativo/ questionário, para demonstrar os tipos e padrões de dados coletados pelo sistema, suas possíveis análises em estudo de caso, além de apresentar o próprio aplicativo. Os avanços tecnológicos propostos contribuem para a ampliação da qualidade dos dados obtidos e do envolvimento do usuário no momento da aplicação do questionário. Desse modo, espera-se que os resultados da pesquisa favoreçam uma melhora na qualidade das habitações.

Palavras-chave: Avaliação pós-ocupação. Inovação tecnológica. Qualidade espacial e ambiental. Habitação.

\begin{abstract}
This paper presents part of the research studytitled "How Do You Live: PostOccupancy Evaluation (Poe) Interactive System on Housing Quality in Digital Media", through a case study based on a post-occupationassessmentusing a computer application. The studyrepresents a TechnologicalInnovation project carried out through a partnership between the Computer College and College of Architecture and Urbanism and Design. The main results include the development of an interactive app/questionnaire named "How Do You Live", connected to a post-occupational assessment management (POEs) database, named "POEDIGITAL SYSTEM". The article intends to use one of the application / questionnaire validation tests, carried out in the current stage of the research, to demonstrate the types and patterns of data collected by the system, their possible analysis in a case study, in addition to presenting the application itself. The technological advances proposed, contribute to increase the quality of the data obtained and the user involvement during the questionnaire application. Thus, it is expected that the research results will favor an improvement in the quality of housing. Keywords: Pos-occupancy evaluation. Technology innovation. Spatial and environmental quality. Housing.
\end{abstract}

Luisa Trevisan dos Uber

Recebido em 05/12/19 Aceito em 01/04/20

VILLA, S. B.; BRUNO, D. C.; SANTOS, A. L. T. dos. Avaliação pós-ocupação da qualidade na habitação por meio do aplicativo "Como você mora?": estudo de caso na cidade de Uberlândia. Ambiente Construído, Porto Alegre, v. 20, n. 3, p. 225-247, jul./set. 2020.

ISSN 1678-8621 Associação Nacional de Tecnologia do Ambiente Construído.

http://dx.doi.org/10.1590/s1678-86212020000300426 


\section{Introdução}

A inovação tecnológica que promove o desenvolvimento de instrumentos de APO tecnologicamente avançados é muito utilizada pelo grupo [MORA] em boa parte de suas pesquisas e atividades acadêmicas ${ }^{1}$. Nesse sentido, a proposta-chave da pesquisa foi o desenvolvimento do aplicativo "Como você mora?" $(\mathrm{CVM})$, disponível em plataforma Google $\mathrm{Play}^{2}$, utilizando uma interface interativa, que processa uma avaliação pós-ocupação, integrado a um banco de dados intitulado "Sistema APO Digital" , para a coleta e o gerenciamento das respostas. A partir da coleta dos dados obtidos na APO, torna-se possível a geração de gráficos e elaboração de análises as quais auxiliam na verificação dos pontos positivos e negativos dos empreendimentos avaliados, para que seja possível a otimização da investigação da qualidade das habitações. Tal fato é possível devido a avanços alcançados pela tecnologia, como, por exemplo, a possibilidade de maior amostragem e a diminuição do tempo de aplicação e, posteriormente, de tabulação dos dados. A Figura 1 apresenta os produtos que compõem o "Sistema APO Digital", cada um elaborado com uma determinada finalidade. Cada produto se configura separadamente como uma ferramenta de APO, cada qual com seu questionário e objetivos de avaliação, os quais estão ligados ao banco de dados (Sistema APO Digital). As respostas obtidas pelos aplicativos são enviadas ao banco de dados que armazena essas informações, tornando possível a geração de gráficos e análises comparativas dos resultados de diferentes produtos. Nesse sentido, o aplicativo "Como você mora?" e o "APO Web" servem, respectivamente, como meios de realização da APO e geração e consulta de resultados.

A justificativa do enfoque do trabalho na inovação tecnológica se dá no objetivo de tornar o processo da APO mais eficiente, através do uso de interfaces gráficas, projetadas para dispositivos móveis, que incorporam mecânicas de jogos digitais. A partir da abordagem da interação homem-computador (IHC), uma aplicação que leva o usuário a conhecer melhor a lógica do designer pode propiciar-lhe um uso mais criativo, eficaz e produtivo (PREECE; ROGERS; SHARP, 2005).

\section{Figura 1 - Produtos do Sistema APO Digital}

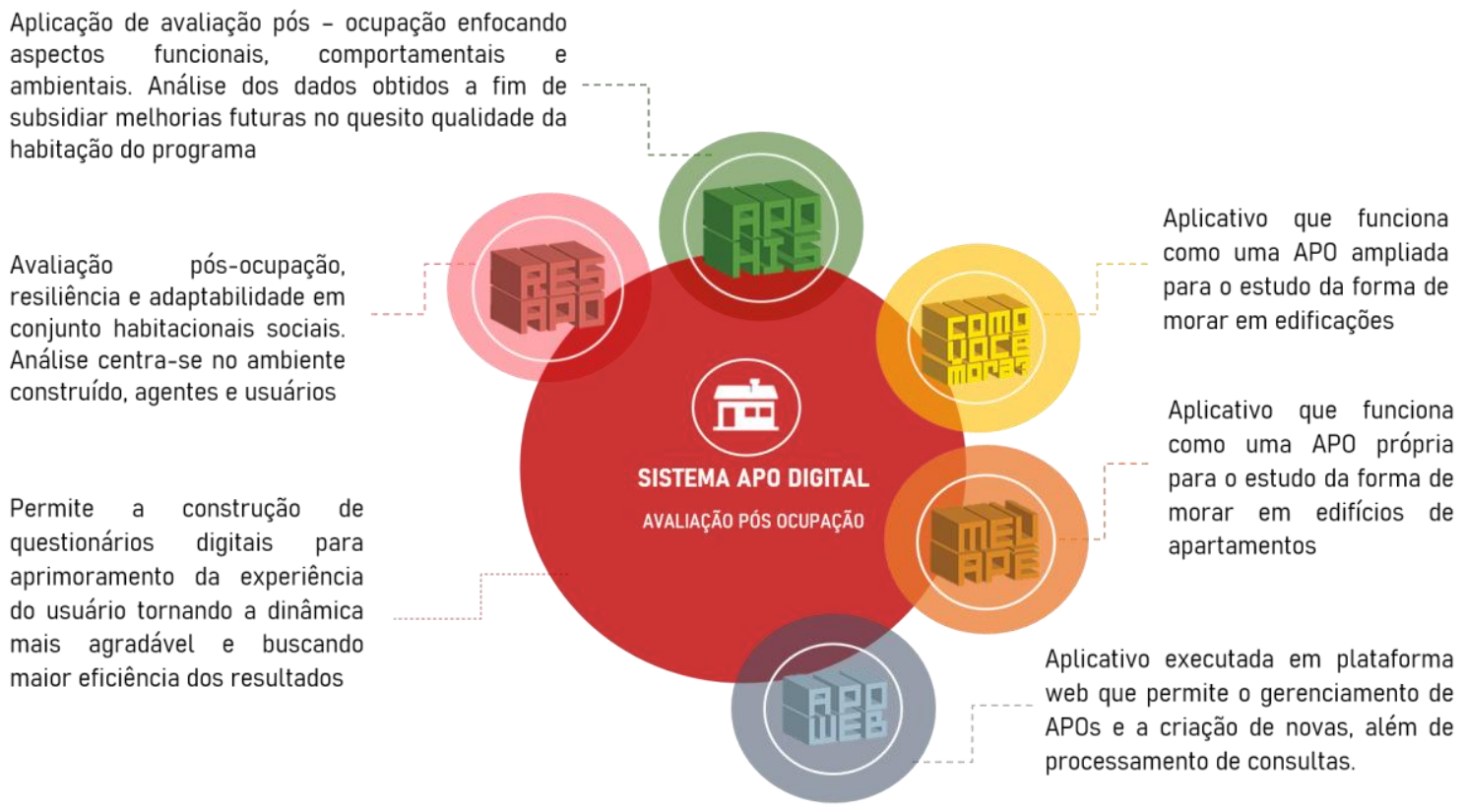

${ }^{1} \mathrm{~A}$ busca por avanços metodológicos na área de APO é meta principal das pesquisas realizadas no [MORA] pesquisa em habitação - grupo de pesquisa registrado no CNPq (Conselho Nacional de Desenvolvimento Científico e Tecnológico - Brasil) vinculado à Faculdade de Arquitetura e Urbanismo e Design da Universidade Federal de Uberlândia (FAUeD/UFU), Brasil - ver mais informações em http://morahabitacao.com/.

${ }^{2}$ Disponível em: https: / /play.google.com/store/apps/details?id=com.morahabitacao.ComoVoceMora.

${ }^{3}$ O Sistema APO Digital foi idealizado nas pesquisas: [APO DIGITAL 1] Avaliação pós-ocupação em apartamentos com interfaces digitais (2012-2014 - Demanda Universal - FAPEMIG Nº1/2011); [APO DIGITAL 2] Avaliação pós-ocupação funcional, comportamental e ambiental em apartamentos com interfaces digitais: aprimoramento do software, interface e aplicacão (2014-2016 - Demanda Universal - FAPEMIG NNo1/2013); [COMO VOCÊ MORA?] Sistema interativo de avaliação pós-ocupação da qualidade do habitar em meios digitais (2014-2017 CNPq-MCTI No 22/2014) e [COMO VOCÊ MORA?] Sistema interativo de APO da qualidade do habitar em meios digitais. ETAPA 2_testes e ajustes no banco de dados. (2018-2020 - CNPq - PIBIT e PROGRAD/DIREN/UFU). 
Diante disso, as reflexões expostas neste artigo correspondem à etapa da pesquisa a qual consiste na realização de testes e ajustes dos produtos desenvolvidos, com o intuito de aprimorar tais ferramentas. Para tanto, foi realizado um teste de usabilidade, utilizado como pré-teste, e posteriormente um teste definitivo utilizando o método de estudo de caso - através da aplicação de uma APO na cidade de Uberlândia (MG), tendo como ferramenta o aplicativo CVM. Para além dos resultados relacionados ao desempenho do aplicativo nos testes, será dado enfoque aos resultados quantitativos obtidos através da APO, a fim de demonstrar os tipos e padrões de dados coletados pelo sistema e suas possíveis análises em estudo de caso, acerca da qualidade da habitação.

\section{Referencial teórico}

Considerando a importância do morar para o ser humano, justifica-se o amplo conhecimento de como os habitantes de nossas cidades estão sendo abrigados, suas necessidades e o impacto decorrente dessas moradias no meio ambiente (SARAMAGO; VILLA; SILVA, 2017), sendo, desse modo, importante avaliar a qualidade do habitar, tanto em suas dimensões objetivas, quanto subjetivas (STEVENSON, 2019; BAKER; STEEMERS, 2019).

A busca por soluções projetuais mais adequadas se dá continuamente, tanto do ponto de vista funcional e formal da arquitetura, quanto do urbanismo. Apesar disso, nossas cidades continuam a receber anualmente centenas de unidades habitacionais que contrariam os princípios básicos de habitabilidade (AMORE; SHIMBO; RUFINO, 2015; VILLA; ORNSTEIN, 2013; VILLA; SARAMAGO; GARCIA, 2015). Assim, evidencia-se a necessidade de entender a relação entre o comportamento humano no espaço doméstico e a qualidade da habitação, como forma de melhorar a satisfação e o desempenho dos projetos. Essa melhoria inclui a montagem e observação de bancos de dados alimentados por avaliações, que incluam técnicas de percepção física do ambiente construído, além da interação entre esse ambiente e o comportamento dos usuários (VILLA, 2008; MALLORY-HILL; PREISER; WATSON, 2012; ONO et al., 2018). Portanto, as informações fornecidas por pesquisas de APO, sobre as necessidades e a satisfação dos moradores, devem alimentar integralmente todas as fases do processo de projeto (PREISER; VISCHER, 2005; STEVENSON; LEAMAN, 2010; VAN DER VOORDT; VAN WEGEN, 2013; STEVENSON; BABORKSA-NAROZNY, 2018).

Com relação à inovação tecnológica, seu exercício se justifica à medida que o desenvolvimento de interfaces digitais e a maior interação entre homem e computador potencializam processos educativos ao usuário, reforçando, assim, novas agendas em relação à aplicação de APO como processo e não somente como produto em si (COLE, 2007). Além disso, foram utilizadas metodologias originárias do UXDesign ${ }^{4}$, do UIDesign $^{5}$ e da Gamificação ${ }^{6}$, a fim de dar à interface a competência para não só cumprir seu principal objetivo (o de avaliar o comportamento e necessidades do usuário), mas para fazer com que o processo de avaliação seja uma experiência positiva, lúdica e interativa para os usuários (SANTAELLA, 2005; UNGER; CHANDLER, 2009; AMBROSE; HARRIS, 2012).

\section{Método}

A partir do delineamento metodológico geral, a pesquisa foi planejada em três grandes etapas:

(a) desenvolvimento de bases teóricas e tecnológicas para o Sistema APO Digital (2012-2014);

(b) desenvolvimento dos aplicativos, incluindo o "Como você mora?", e do banco de dados do Sistema APO Digital (2014-2017); e

(c) aprimoramento e correção dos produtos e realização de testes (2018-2020).

As etapas de trabalho da pesquisa foram divididas nos seguintes itens:

(a) pesquisa bibliográfica sobre tipologias, aspectos e avaliação do morar;

(b) categorização e definição dos principais atributos abordados na avaliação em relação a tipologias, aspectos e avaliação do morar;

\footnotetext{
${ }^{4}$ User Experience Design - design de experiência do usuário.

${ }^{5}$ User Interface Design - design de interface de usuário.

${ }^{6}$ Gamificação é, basicamente, usar ideias e mecanismos de jogos para incentivar alguém a fazer algo.
} 
(c) identificação dos limites e recortes do sistema de avaliação a ser desenvolvido a partir das definições acima, caracterizando e definindo suas partes, ferramentas, funcionamento e seus objetivos;

(d) desenvolvimento do sistema interativo de APO em meios digitais em protótipos funcionais (computadores, PC) - banco de dados + questionários/aplicativo CVM;

(e) aplicação de pré-testes das ferramentas do sistema em protótipos funcionais com a população de Uberlândia;

(f) desenvolvimento do sistema interativo de APO em meios digitais (internet, tablets e smartphones);

(g) aplicação do pré-teste do questionário interativo utilizando o método do teste de usabilidade em tablets e smartphones;

(h) aplicação do questionário interativo em estudo de caso na cidade de Uberlândia;

(i) avaliação do sistema e realização de ajustes necessários;

(j) aplicação de um novo teste de usabilidade do sistema interativo de APO revisado emtablets e smartphones;

(k) aplicação do questionário interativo de APO revisado em estudo de caso na cidade de Uberlândia; e

(1) disponibilização do sistema interativo de APO em meios digitais para a comunidade.

Por se tratar de um amplo projeto de pesquisa ${ }^{7}$, que envolve várias etapas de execução, neste artigo será dada ênfase somente à etapa "h", realizada durante o ano 2019, apresentando os resultados da aplicação do questionário para demonstrar os tipos e padrões de dados coletados pelo sistema e suas possíveis análises em estudo de caso, relativas à qualidade na habitação nos contextos estudados.

\section{Metodologia do teste de usabilidade do questionário/aplicativo CVM}

Como ponto de partida inicial para verificar a funcionalidade do aplicativo/questionário CVM, realizou-se um "teste de usabilidade" 8 , visando à coleta de dados comportamentais, a fim de aprimorar sua facilidade de uso. A metodologia utilizada para o teste denomina-se "ThinkAloud" ou "Verbalização de procedimentos", que consiste na avaliação da usabilidade do sistema, incentivando o usuário a pensar em voz alta enquanto o utiliza. Para a realização do teste, foram selecionados diferentes perfis de usuários, de forma a contemplar todas as dificuldades e impressões possíveis.

\section{Metodologia do teste em estudo de caso do questionário/aplicativo CVM}

Para a aplicação do questionário/aplicativo CVM, foi utilizada a metodologia de estudo de caso (YIN, 2010), pois ela é utilizada em análises qualitativas, como estratégia, quando se procura responder questões do tipo "como" e "por quê?" determinados fenômenos ocorrem, nos quais as explicações dos fatos decorrem da profundidade da análise dos casos. Dessa forma, foi definido que seria feita a seleção de dois empreendimentos como estudo de caso, no qual seria aplicada a APO utilizando o aplicativo CVM. A seleção dos casos foi guiada por critérios pré-estabelecidos, de forma que pudesse ser feita uma análise comparativa a partir dos resultados obtidos.

\section{Estrutura e funcionalidades do questionário/aplicativo CVM}

O aplicativo "Como você mora?" se organiza em sete seções, as quais contêm questões agrupadas e separadas por assunto, com cerca de 120 em sua totalidade (Figura 2). Conceitualmente, o aplicativo/questionário contém duas dimensões: a dimensão da investigação - perguntas que visam investigar o desempenho da edificação e a satisfação e desejos do usuário através de suas respostas - e a dimensão da informação - leva ao usuário conhecimento sobre a problemática discutida em determinadas perguntas, como demonstra a Figura 3. A primeira versão dessa dimensão informativa foi elaborada tomando como base os textos informativos e os mapas interativos. Os textos aparecem em forma de telas informativas que oferecem feedbacks, com informações acerca de práticas sustentáveis, e os mapas mostram

\footnotetext{
${ }^{7}$ A pesquisa “Como Você Mora” iniciou-se em 2012 e conta com 31 publicações de artigos e 4 relatórios até o presente momento.

${ }^{8}$ Segundo Zandoná (2017) os testes de usabilidade são técnicas nas quais os usuários interagem com um produto ou sistema para realizar uma tarefa, com objetivos definidos, em um dado cenário, visando à coleta de dados comportamentais, e melhorar a facilidade de uso de
} um produto/sistema. 
locais de interesse na cidade, como ecopontos, locais de comércio, etc., mas pretende-se ainda ampliar essa dimensão em pesquisas futuras.

\section{Figura 2 - Estruturação do game em seções}

\begin{tabular}{|c|c|c|c|}
\hline & & SEÇÖES & TEMAS \\
\hline 1 & & SOBRE VOCE & Gênero, idade, escolaridade, moradores, funcionários, renda familiar, profissão \\
\hline 2 & Ân & MORADIA ANTERIOR & Tipologia, estado de aquisição, grau de satisfação, tempo de permanência \\
\hline 3 & & MORADIA ATUAL & $\begin{array}{l}\text { Localização: } \\
\text { SOBRE O BAIRRO: grau de identificação, equipamentos urbanos, presença de comércios, } \\
\text { espaços públicos, organização de moradores, satisfação e integração }\end{array}$ \\
\hline 4 & & CONJUNTO & Tipologia, blocos, equipamentos coletivos \\
\hline 5 & & EDIFICAÇÃO & $\begin{array}{l}\text { Justificativa da escolha da moradia, pontos negativos, pavimentos, grau de satisfação, } \\
\text { delimitações e barreiras }\end{array}$ \\
\hline 6 & & UNIDADE & $\begin{array}{l}\text { Estado de aquisição, tipologia, significado, adaptação e identificação, adequação do } \\
\text { layout, renda extra, satisfação, influência da tecnologia, área útil, ambientes e quantidade, } \\
\text { flexibilidade dos ambientes, satisfação de cada ambiente, reformas e justificativas, insola- } \\
\text { ção, atividades }\end{array}$ \\
\hline 7 & & HÁBITOS SUSTENTÁVEIS & $\begin{array}{l}\text { Economia de água e de energia elétrica, uso de energia solar, gestão do lixo, consumo de } \\
\text { alimentos orgânicos, uso de ecobags, plantas, meios de transporte utilizados, feedbacks }\end{array}$ \\
\hline
\end{tabular}

Figura 3 - Dimensões do aplicativo

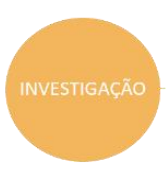

Dimensão que investiga o desempenho da edificação e a satisfação e desejos do usuário

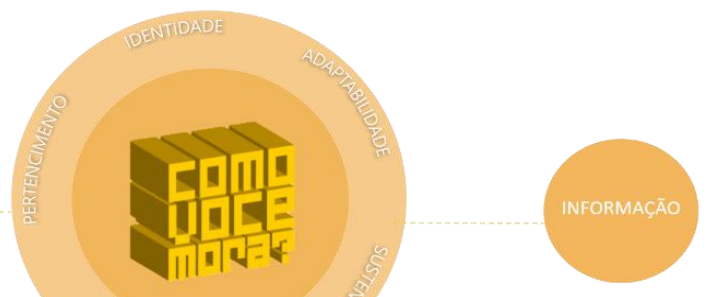

Dimensão que leva ao usuário conhecimento sobre a problemática discutida na pergunta em questão
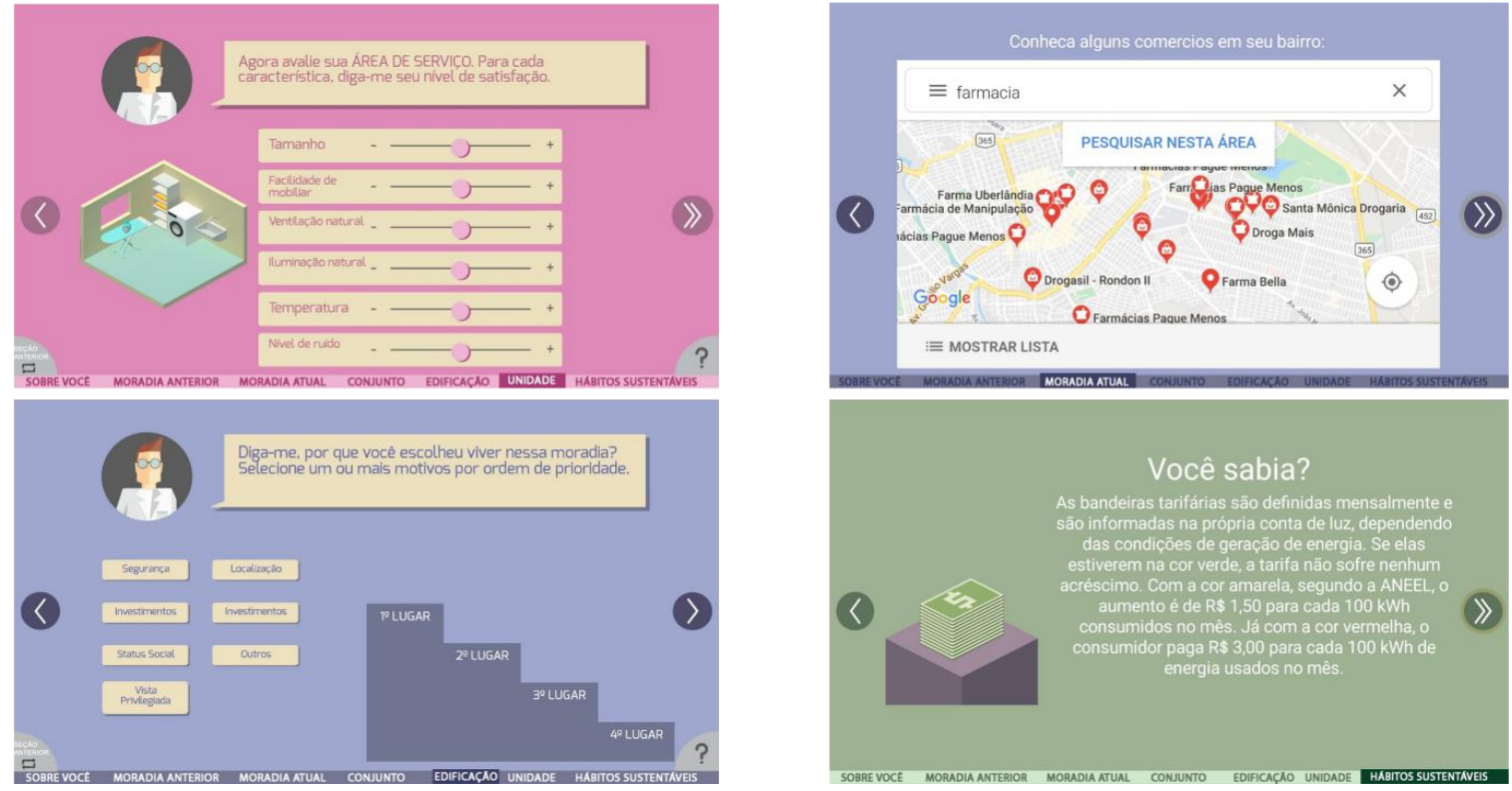
As respostas das APO, realizadas através do aplicativo CVM, são enviadas e armazenadas em um banco de dados. Tal fato faz com que a geração de gráficos seja automática e eles possam ser utilizados para realização das análises dos resultados. Por ser um aplicativo com muitas perguntas a serem tabuladas, o uso da tecnologia e do banco de dados tornou muito mais rápido e eficiente esse processo, comparado aos questionários em papel. Além disso, a geração automática dos gráficos permitiu maior fidelidade dos resultados em comparação à coleta manual dos dados.O aplicativo também se utiliza de elementos gráficos que buscam estabelecer uma conexão mais forte entre o respondente e o questionário/aplicativo (Figura 4), facilitando a dimensão educacional do produto e ampliando a confiabilidade dos resultados.

\section{Resultados e discussão}

\section{Aplicação da APO com o produto “Como você mora?”}

Para realização da APO, foram selecionados dois empreendimentos como estudo de caso, sendo um condomínio de casas e um de apartamentos, visando abranger cenários distintos, oferecidos pelo aplicativo. Para a escolha foram estabelecidos critérios como ano de construção, faixa do Programa Minha Casa Minha Vida (PMCMV), preço dos imóveis, etc. (Figura 5), de modo que os empreendimentos escolhidos possuíssem valores próximos em cada critério, no intuito de validar a comparação.

A partir da definição dos empreendimentos para o estudo de caso, coletou-se o material gráfico (Figura 6) e técnico relativo aos respectivos empreendimentos, sendo esse material submetido à análise, a fim de verificar se os projetos atendem aos requisitos do Código de Obras da cidade de Uberlândia, Lei Complementar n. 524 (UBERLÂNDIA, 2011), da Norma de Desempenho NBR 15575 (ABNT, 2013) e da cartilha completa do Programa Minha Casa Minha Vida (CAIXA, 2009). A amostragem definida foi de 50\% do número de unidades ocupadas. Dessa forma, no empreendimento A, que possui 76 unidades ocupadas, a amostragem foi de 38 unidades, e no empreendimento B, com 88 unidades ocupadas, a amostragem foi de 44 unidades. Após a seleção dos empreendimentos e planejamento do teste, iniciou-se a aplicação da APO nos empreendimentos selecionados. Foram utilizados tablets, como ferramenta para a execução do aplicativo, e a aplicação foi realizada por duas duplas de pesquisadoras, cada dupla utilizando um tabletcomo equipamento. A fim de alcançar maior eficiência dos resultados, buscou-se abranger o máximo de possibilidades de implantação das unidades dos dois empreendimentos, levando em consideração a insolação, ventilação, visibilidade, proximidade com áreas de lazer, entre outras variáveis. As Figuras 7 e 8 mostram os mapas de aplicação dos dois empreendimentos, indicando as unidades nas quais ocorreu a aplicação da APO.

Figura 4 - Exemplos de ícones presentes em diferentes seções do questionário/aplicativo CVM

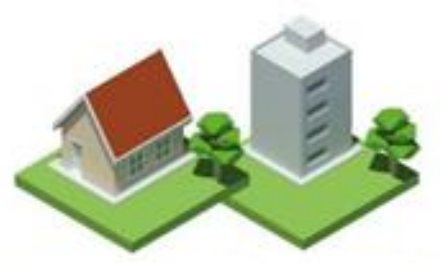

DEFININDO DA TIPOLOGIA DA MORADIA

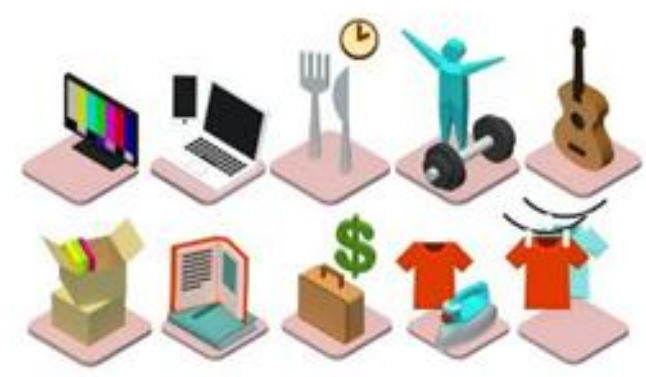

DEFININDO AS ATIVIDADES QUE REALIZA EM CADA CÖMODO

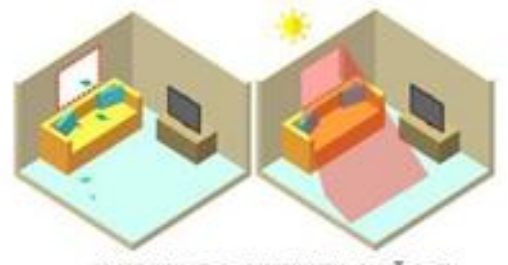

AVALIANDO A VENTILAÇĀO E INSOLAÇĀO DA SALA DE ESTAR

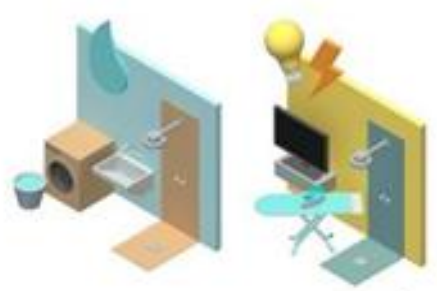

AVALIANDO A ECONOMIA DE ÁGUAE ENERGIA 
Figura 5 - Empreendimentos definidos

\begin{tabular}{|c|c|c|}
\hline CRITÉRIOS & EMPREENDIMENTO A & EMPREENDIMENTO B \\
\hline Tipologia & Apartamentos 冏 & Casas \\
\hline Ano construção & 酒岗 & 2012 \\
\hline Área terreno & $4.720 \mathrm{~m}^{2}$ & $24.500 \mathrm{~m}^{2}$ \\
\hline Faixa MCMV & sm & s. \\
\hline Tipologias das unidades & 2 (2 e 3 quartos) & 1 (2 quartos) \\
\hline Qtde plantas & 7 variações 대비 & 1 planta espelhada $\left[F_{E}\right.$ \\
\hline $\begin{array}{l}\text { Área útil unidades } \\
\text { aproximadamente }\end{array}$ & $47 m^{2}$ a $67 m^{2}\left[m^{2}\right.$ & $36 \mathrm{~m}^{2}$ \\
\hline Preço de lançamento & 120 á 220 mil $\$$ & $80 \mathrm{mil}$ \\
\hline $\mathbf{N}^{\circ}$ unidades & 80 & $\widehat{\Lambda}$ \\
\hline $\mathrm{N}^{\circ}$ unidades ocupadas & 달켜 & 结目 \\
\hline $\begin{array}{l}\text { Definição da amostragem } \\
\qquad(50 \%)\end{array}$ & 38 unidades & 44 unidades \\
\hline
\end{tabular}

Figura 6 - Informações sobre os empreendimentos

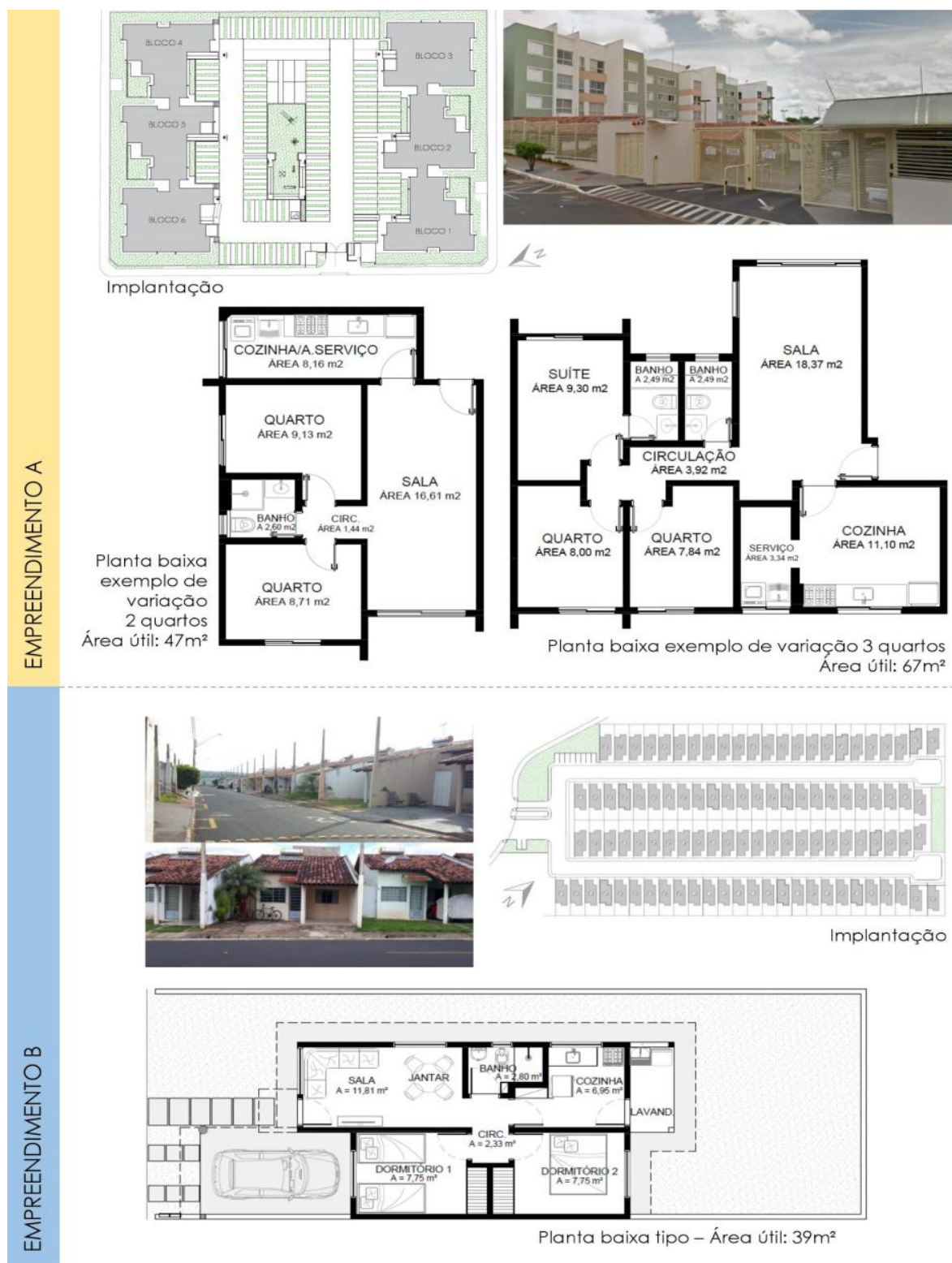


Figura 7 - Mapa APO do empreendimento A
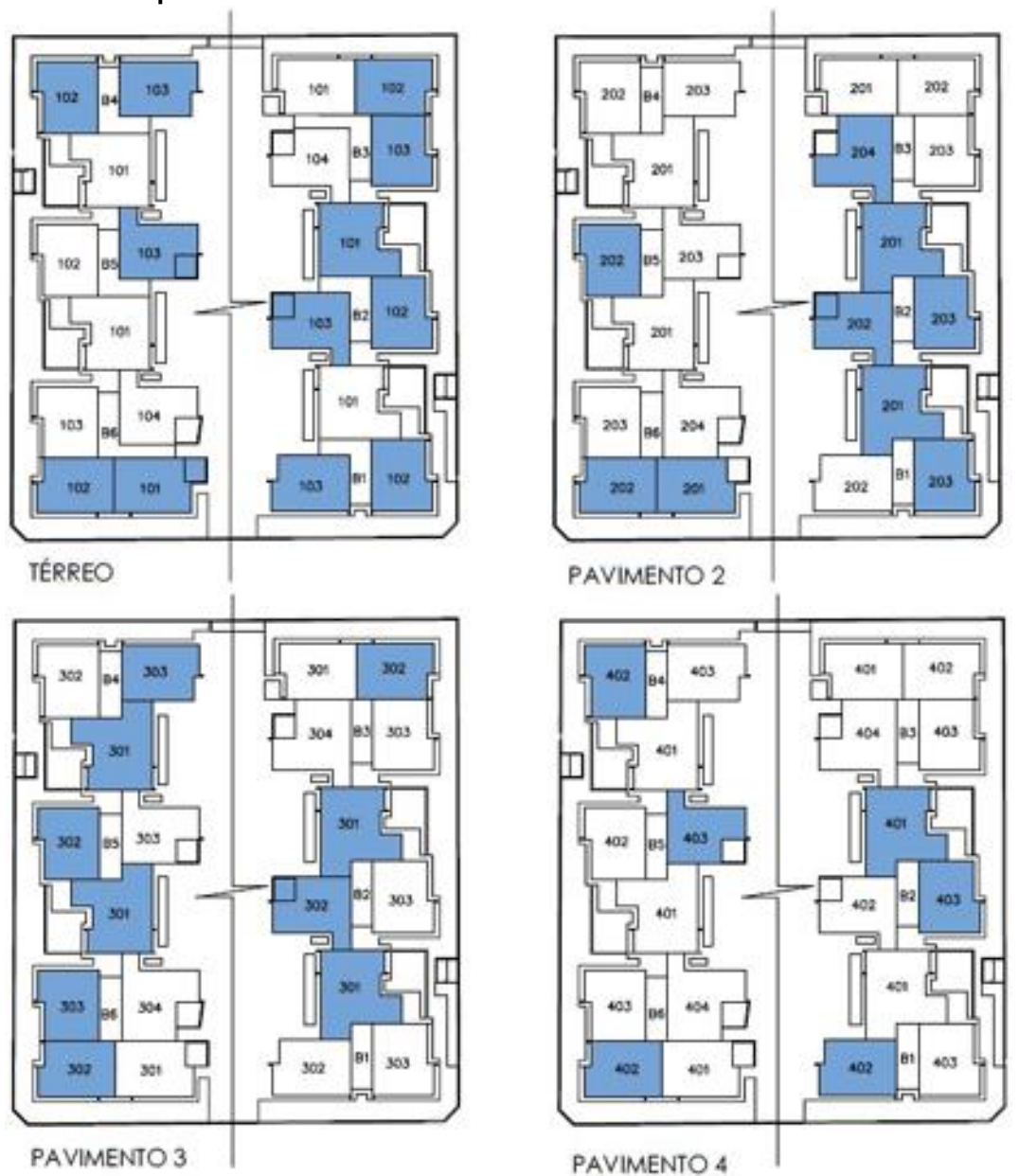

Fonte: construtora responsável, adaptado pelas autoras.

Figura 8 - Mapa APO do empreendimento B

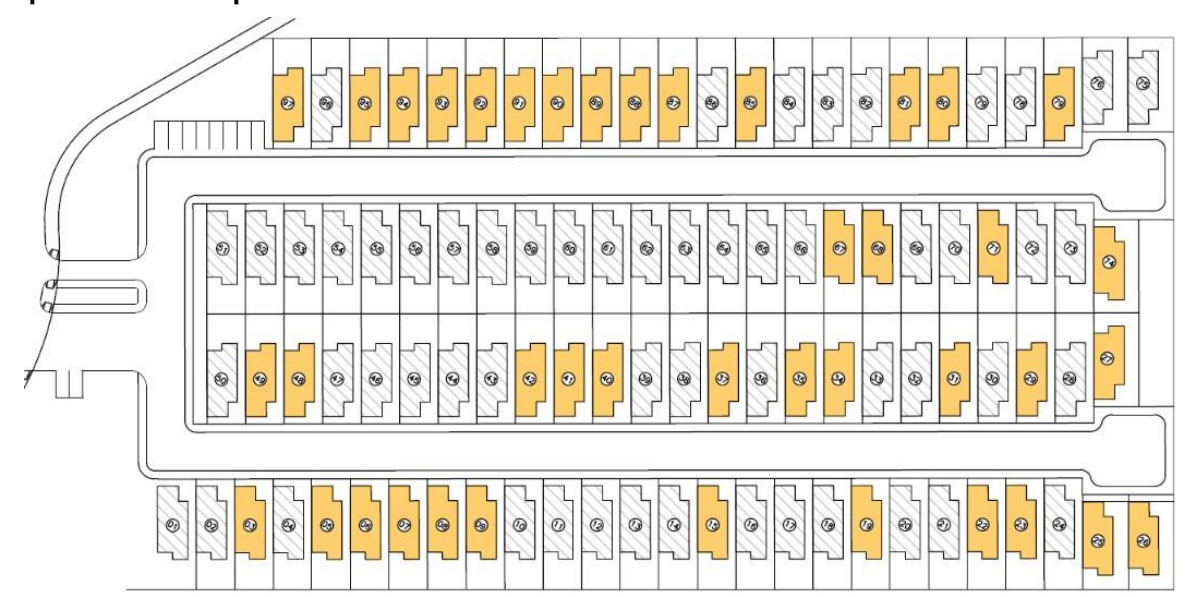

Fonte: construtora responsável, adaptado pelas autoras.

Idealmente, no momento da aplicação, os próprios moradores deveriam manusear os tablets e responder às perguntas do aplicativo. Na maioria dos casos esse fato ocorreu, sendo possível notar uma interação entre o morador e o pesquisador, proporcionando uma experiência diferenciada para o respondente. Excepcionalmente, em alguns casos, essa situação não foi possível devido a dificuldades com o uso desses 
equipamentos, principalmente para idosos. Mesmo nos casos em que os pesquisadores manusearam os tablets, o morador ao lado do pesquisador teve a oportunidade de vivenciar em parte a experiência. As duas simulações estão respectivamente demonstradas na Figura 9.

\section{Análise dos resultados}

A partir das respostas obtidas na aplicação da APO, foi possível a geração de gráficos para organização das informações relativas aos empreendimentos A e B. Foram selecionadas as questões presentes no aplicativo, consideradas mais relevantes, para a comparação entre os empreendimentos e análise da qualidade das habitações. A partir da análise dos dados socioeconômicos, é possível perceber uma discrepância entre os dois empreendimentos, com relação ao nível de escolaridade (Figura 10) e à renda mensal familiar (Figura 11), sendo esses valores inferiores no empreendimento B, em comparação com o empreendimento A.

Previamente à análise da moradia em si, é relevante uma investigação dos bairros nos quais se encontram cada empreendimento. Observa-se uma clara relação entre a localização dos dois bairros e a satisfação dos moradores, visto que o bairro do empreendimento B se encontra em uma localização periférica em relação ao bairro do empreendimento A (Figura 12). A respeito da presença de comércios (Figura 13), por exemplo, fator que influencia diretamente no cotidiano dos moradores, é notório que o bairro do condomínio A é bem servido, enquanto os moradores do condomínio B possuem opiniões distribuídas, principalmente entre "Regular" e "Mal servido", com destaque para grande quantidade de respostas na opção "Muito mal servido". Tal fato se configura como um ponto crítico da análise, pois gera a necessidade de grandes deslocamentos por parte dos moradores em direção a outros bairros.

As perguntas contidas no aplicativo possibilitam a geração de diferentes tipos de gráficos, com várias questões abordadas em uma mesma pergunta. No exemplo das Figuras 15 e 16, é possível perceber que o gráfico gera uma série de dados estatísticos relativos à satisfação com os espaços públicos. A partir da observação desse gráfico, fica evidente a insatisfação dos moradores do empreendimento B com relação ao bairro, apresentando maior percentual de respostas negativas. É possível afirmar, através do gráfico, que a quantidade de espaços públicos no empreendimento B é insatisfatória, assim como a qualidade deles. Além disso, o gráfico da Figura 14 indica que o grau de identificação com o bairro dos moradores do empreendimento B é inferior em relação ao empreendimento A. Esses fatores influenciam diretamente na qualidade de vida e satisfação dos moradores com o bairro em que vivem. No momento da aplicação, foi possível perceber que os moradores do empreendimento B muitas vezes não tinham o conhecimento de nenhuma praça em seu bairro, pois essas se configuram como lotes demarcados para tal finalidade, porém sem qualidade para ser utilizada pela população. A localização dos empreendimentos, aliada a fatores como a baixa qualidade e quantidade dos espaços públicos, podem contribuir para uma não identificação do morador com seu próprio bairro, como no caso do empreendimento B.

\section{Figura 9 - Moradoras respondendo ao questionário/aplicativo CVM}

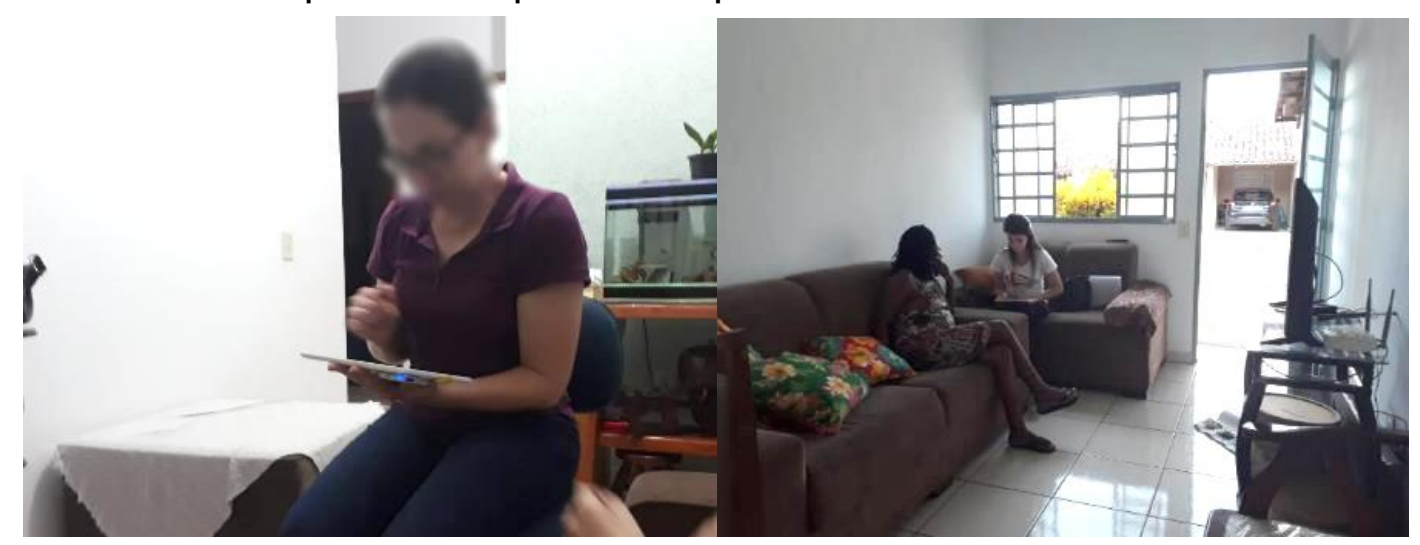


Figura 10 - Gráfico do grau de escolaridade

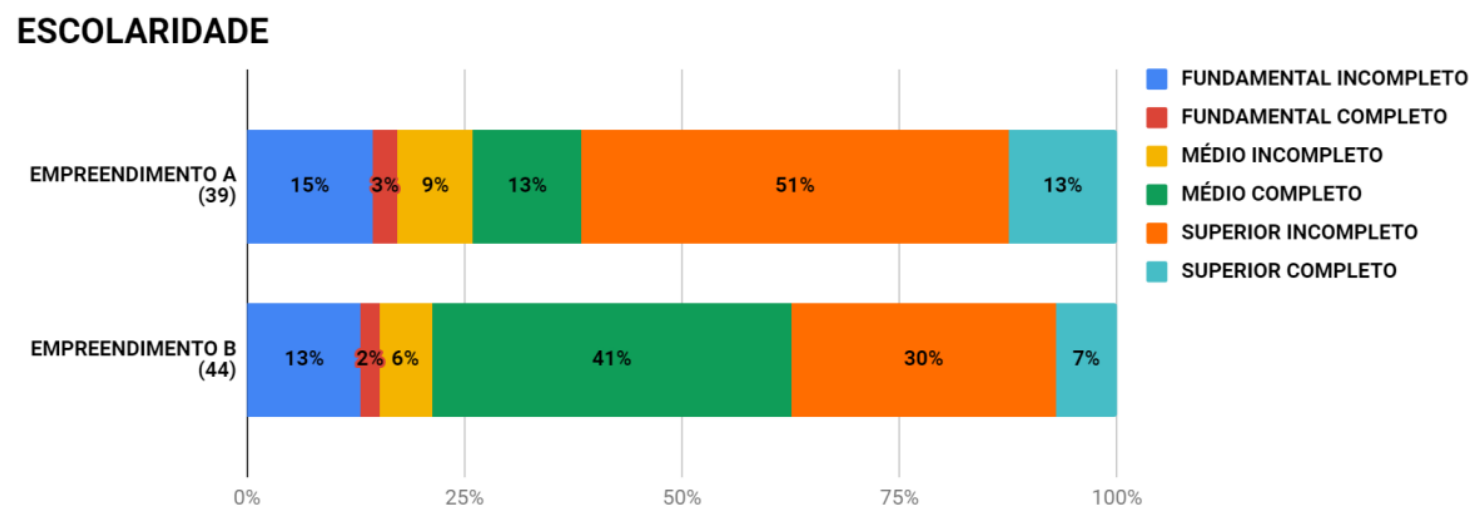

Figura 11 - Gráfico da renda mensal familiar

\section{RENDA MENSAL FAMILIAR}

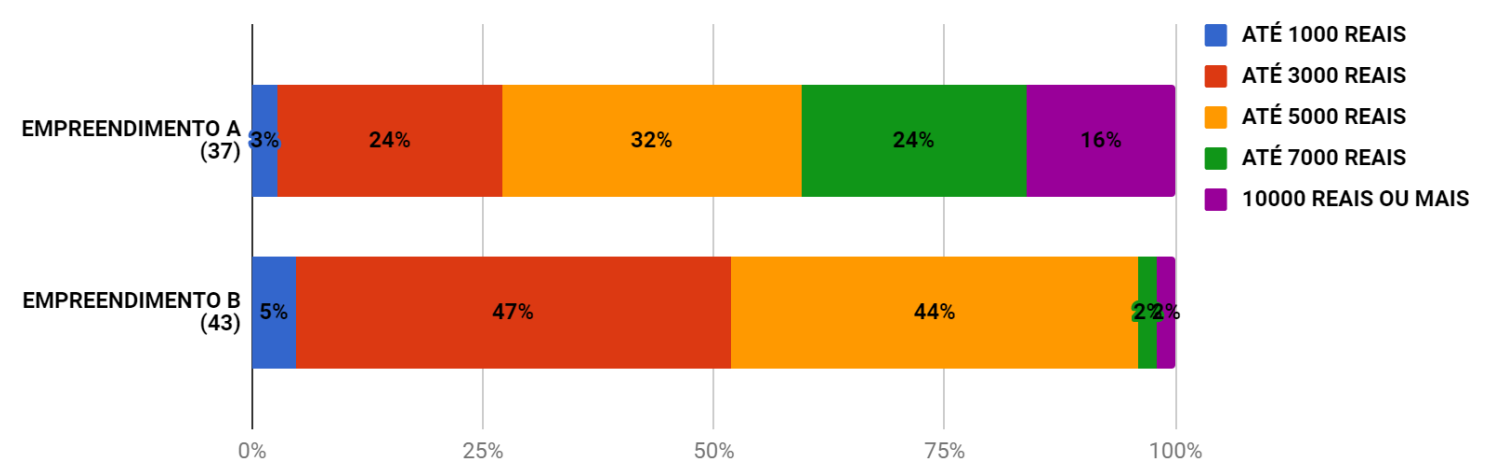

Figura 12 - Localização dos bairros de cada empreendimento

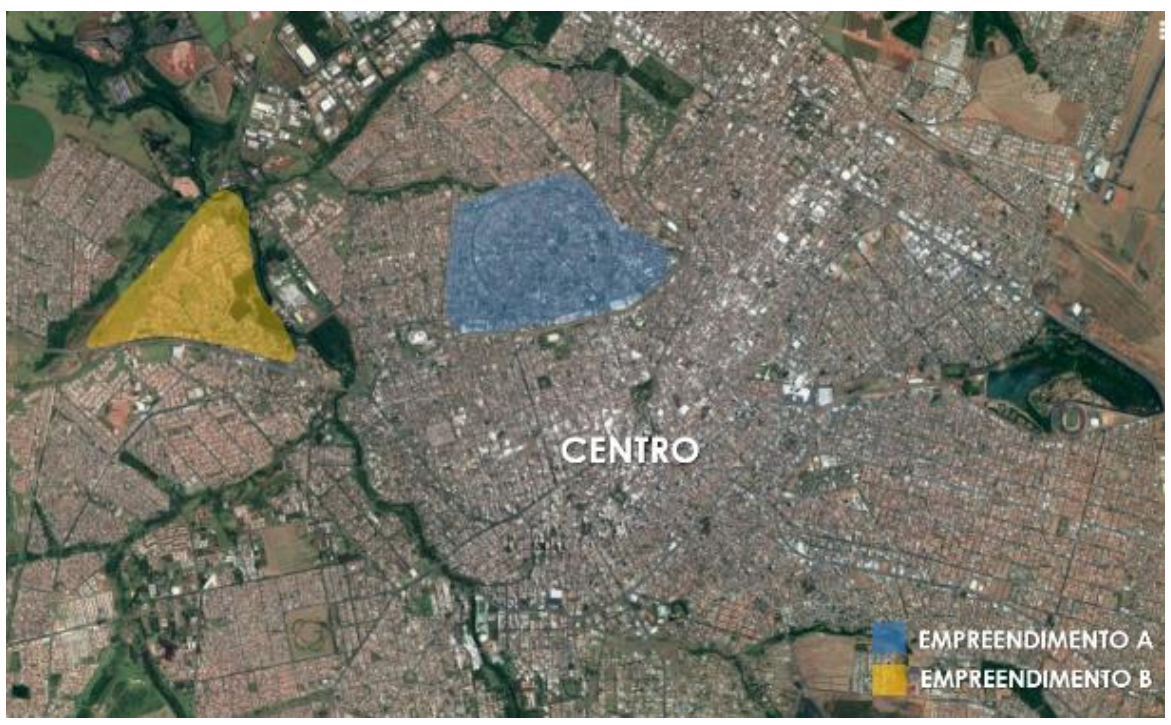


Figura 13 - Gráfico da satisfação com a quantidade de comércios no bairro

PRESENÇA DE COMÉRCIOS NO BAIRRO

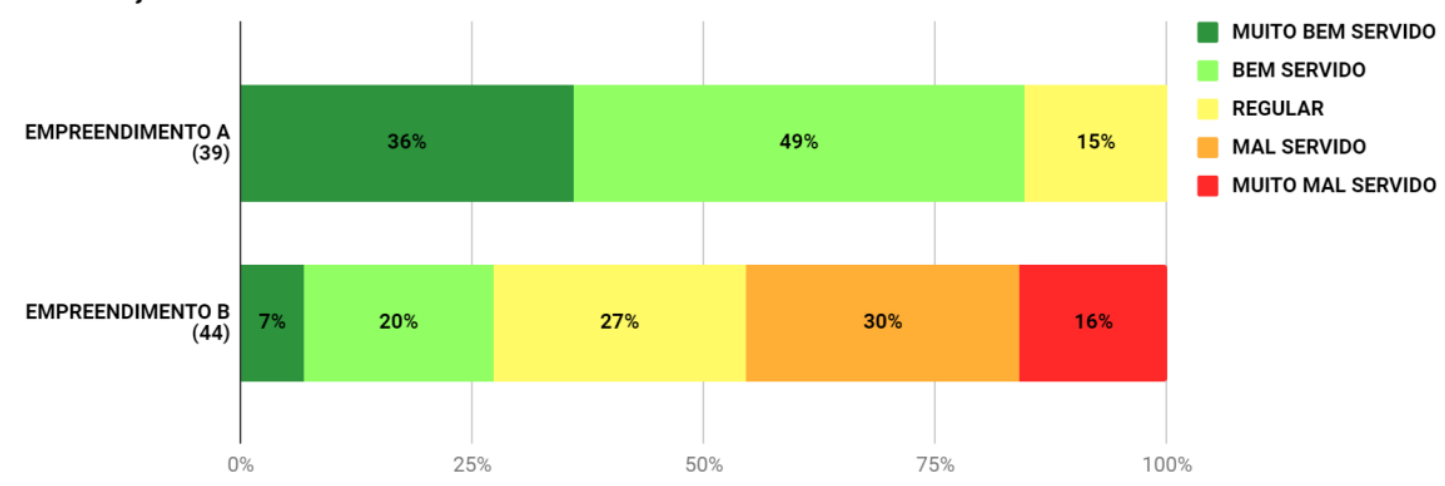

Figura 14 - Gráfico do nível de identificação do morador com seu bairro

IDENTIFICAÇÃO COM O BAIRRO

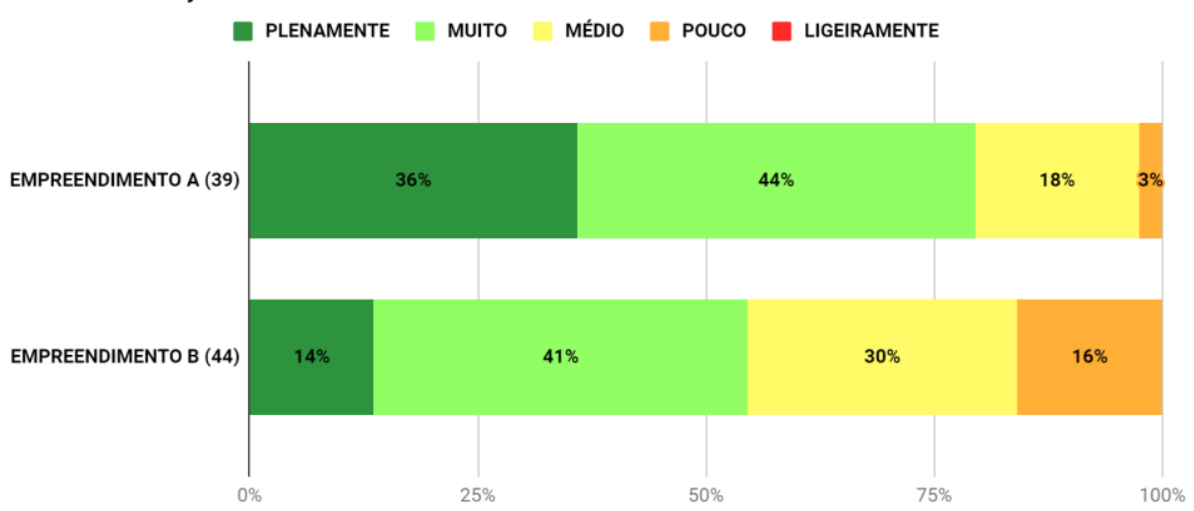

Figura 15 - Gráfico da satisfação com os espaços públicos do bairro do empreendimento A

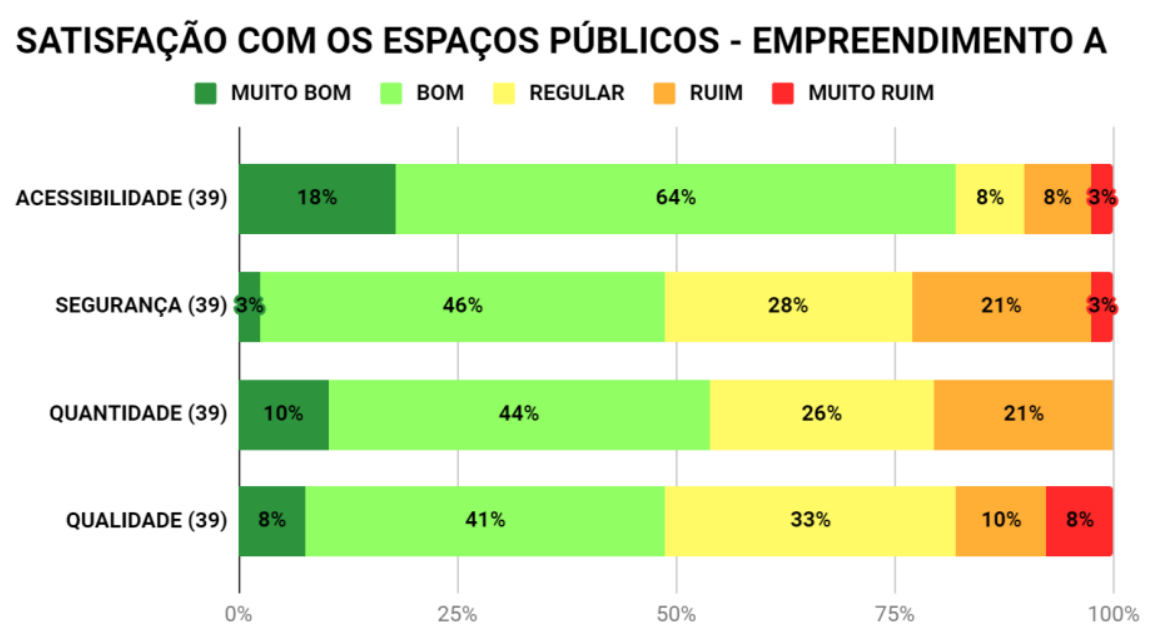


Figura 16 - Gráfico da satisfação com os espaços públicos do bairro do empreendimento B

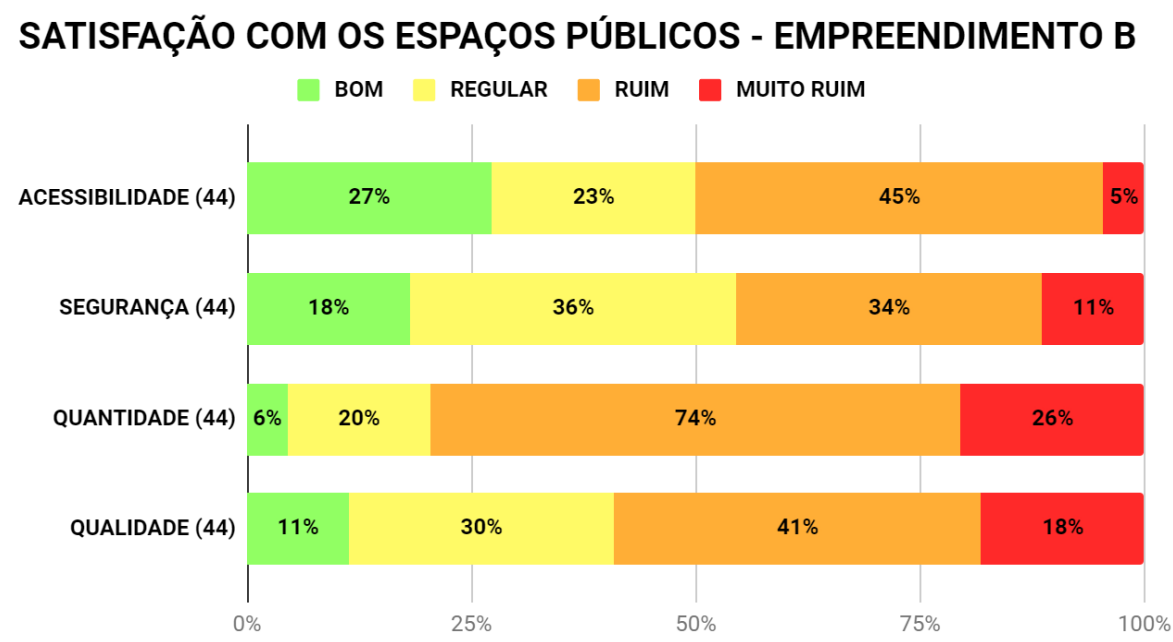

Figura 17 - Justificativa para a escolha da moradia

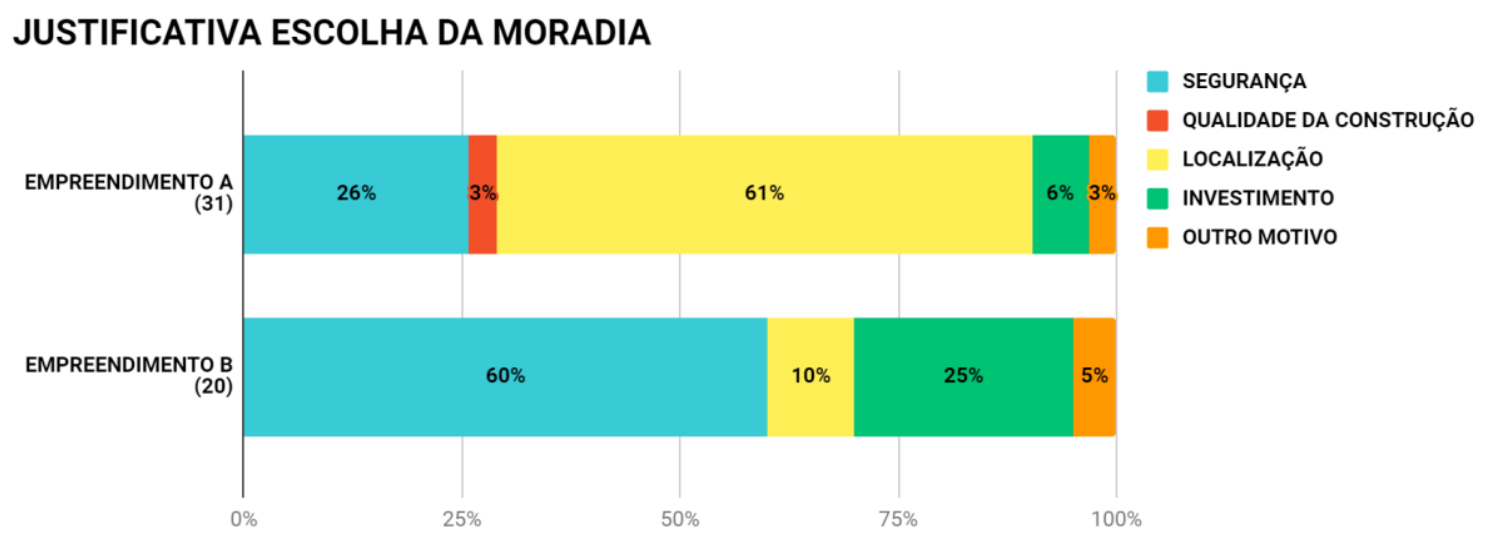

Analisando os dados relativos à justificativa de escolha da moradia (Figura 17), dentre os quesitos abordados na pergunta, o que mais se destaca no empreendimento A é a localização. O mapa da Figura 12 indica que tal bairro possui uma posição mais central, em relação aos pontos âncoras da cidade como shopping center, o próprio centro, o centro cívico e o parque da cidade,em comparação com o bairro do empreendimento B. A grande porcentagem de moradores do empreendimento B escolheu viver nessa moradia pela segurança, o que justifica a escolha de morar em condomínio fechado, visto que o bairro possui índice significativo de violência, e o condomínio fechado com portaria $24 \mathrm{~h}$ auxilia na sensação de segurança, segundo relatos dos moradores.

Em relação ao tamanho da moradia, ambos os grupos o considera bom ou regular (Figura 18), porém existem algumas ressalvas em relação ao grupo B. A primeira possui relação com os dados sobre renda mensal familiar, apresentados na Figura 11. Em virtude da faixa de renda dos moradores do empreendimento B ser mais baixa, seu nível de exigência se torna menor, pois estão satisfeitos com a moradia que se enquadrar em suas condições financeiras. A segunda ressalva está associada às reformas realizadas nas unidades (Figura 20), visto que o empreendimento B possui um número significativo de respostas na opção "remoção ou acréscimo de paredes", sendo que a maioria acrescentou tais paredes a fim de criar um novo cômodo nos fundos da casa, já que ela oferece esse espaço.

No empreendimento A os moradores também consideram o tamanho da moradia como bom; no entanto, sem ter expandido o apartamento, mesmo porque, além da tipologia possuir maiores restrições nesse sentido, no empreendimento avaliado não é permitida a remoção ou acréscimo de paredes. Dessa forma, as reformas realizadas no empreendimento A se concentram em melhorias de acabamento, como pintura (Figura 21) e 
colocação de gesso, além de uma porcentagem grande de moradores que não havia realizado nenhuma das reformas questionadas.

Ainda com relação ao tamanho da moradia, no empreendimento B as maiores insatisfações se dão com relação à cozinha (Figuras 22 a 24). Esse fato, relacionado aos dados relativos às reformas e às percepções no momento da aplicação, aponta que os cômodos acrescentados nos fundos das casas eram, em mais da metade das moradias, utilizados como cozinha e/ou varanda (Figura 25).

Ainda nesse sentido, a Figura 26 apresenta uma casa do empreendimento B que deixou de utilizar a cozinha original da casa e a realocou para os fundos da casa, fazendo uma ampliação da moradia. Tal fato demonstra que o tamanho da cozinha é insuficiente e, sem ser utilizada, esta funciona como um corredor de acesso à área ampliável da casa.

Figura 18 - Gráfico da satisfação com o tamanho da moradia

\section{SATISFAÇÃO COM O TAMANHO DA MORADIA}

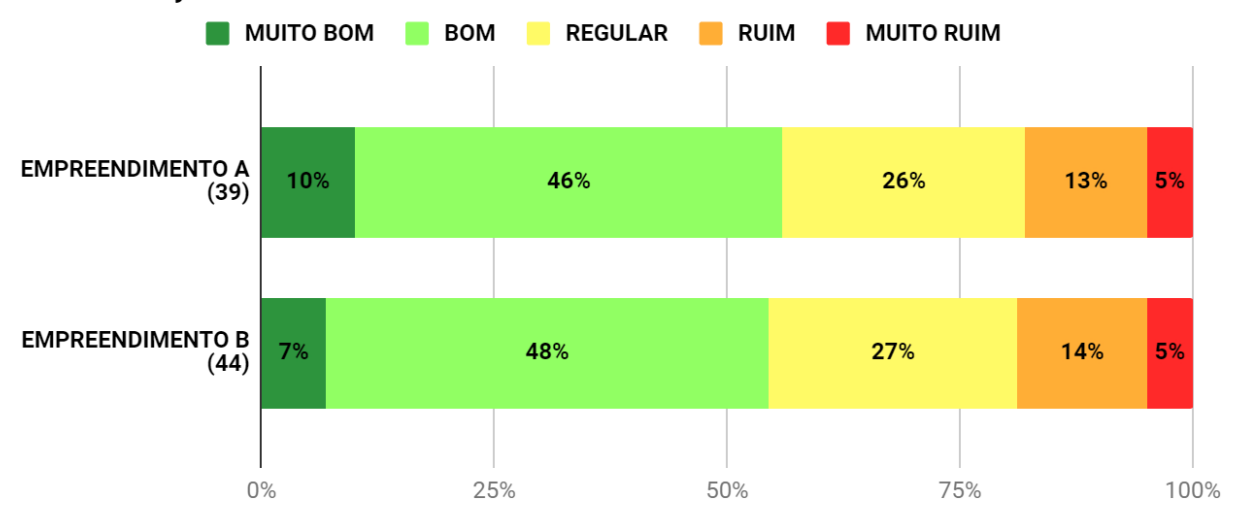

Figura 19 - Planta do empreendimento B com área ampliável

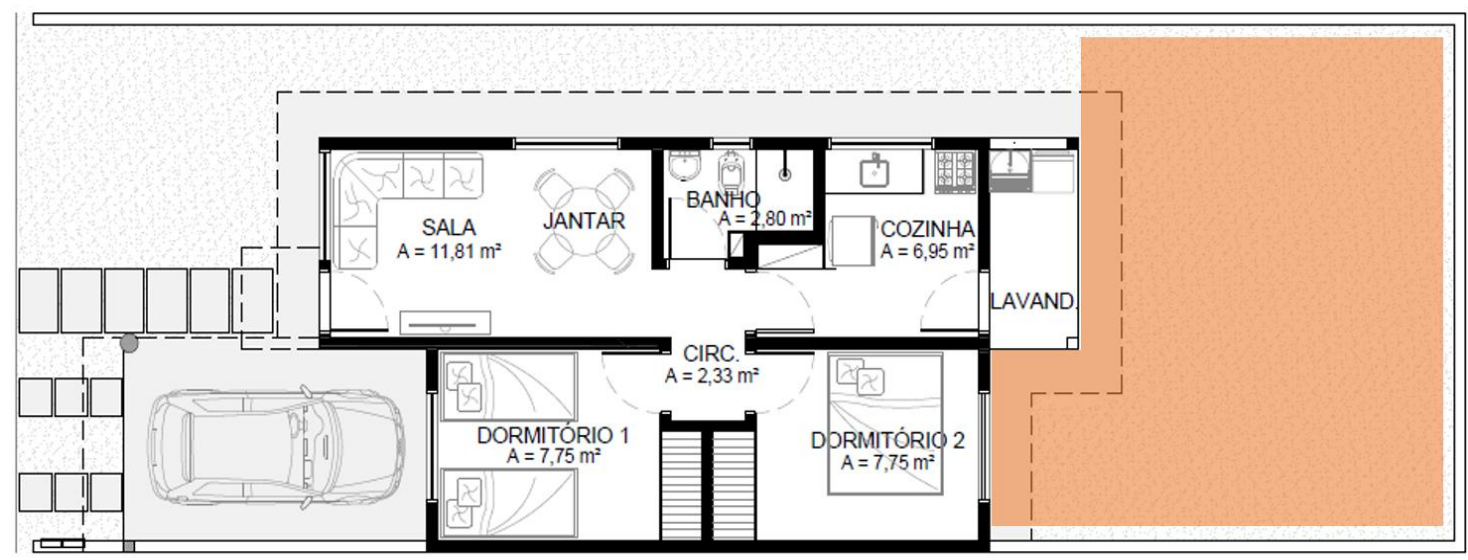


Figura 20 - Gráfico das reformas realizadas na moradia REFORMAS REALIZADAS NA MORADIA

- PERCENTUAL DE MORADORES DO EMPREENDIMENTO A (39)

PERECENTUAL DE MORADORES DO EMPREENDIMENTO B (44)

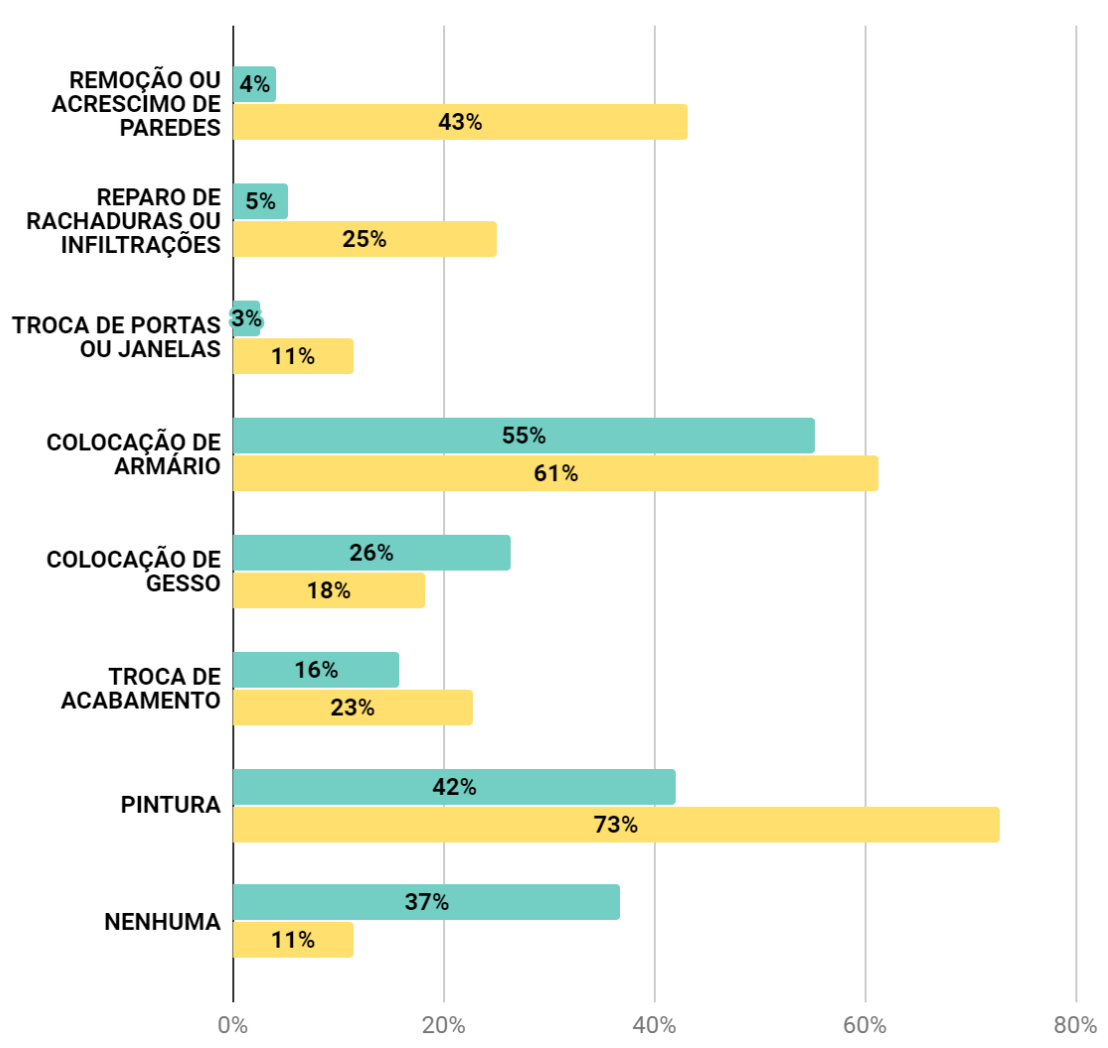

Figura 21 - Exemplos de reformas no empreendimento A: pintura

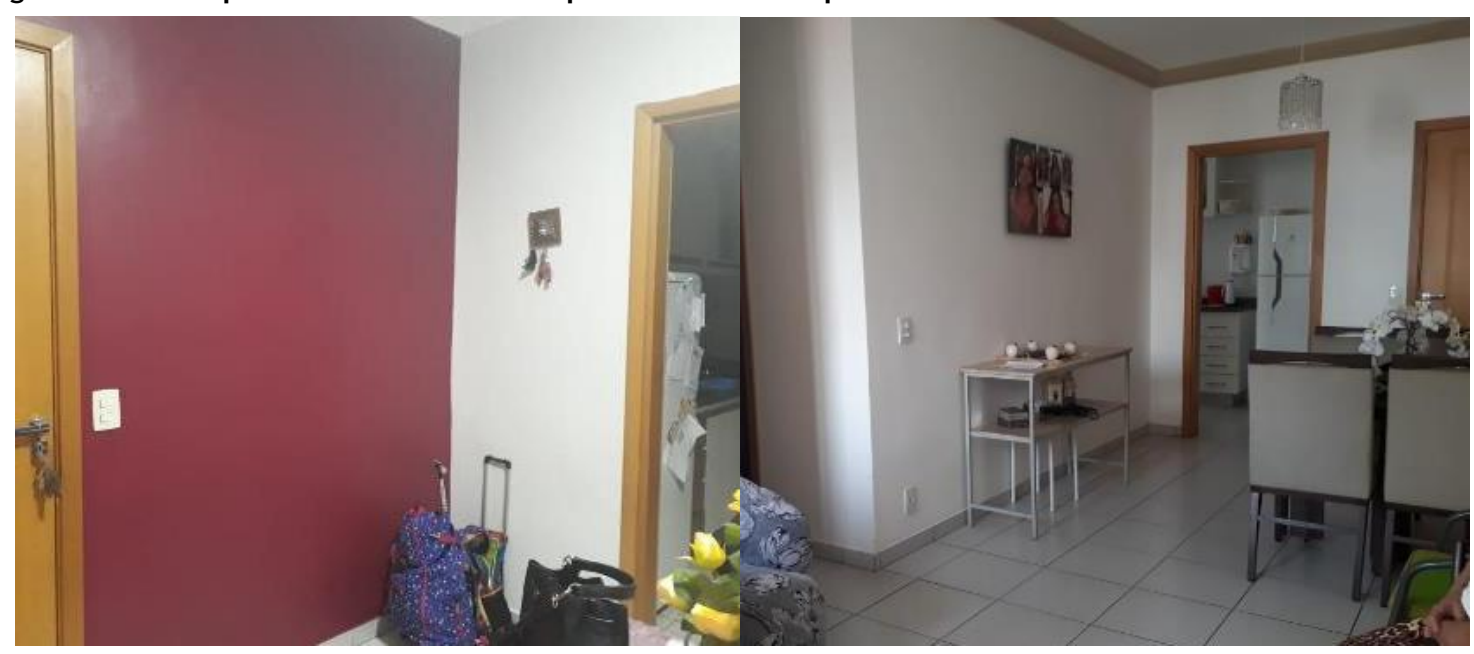


Figura 22 - Gráfico da satisfação com o tamanho da cozinha

\section{SATISFAÇÃO TAMANHO DA COZINHA}

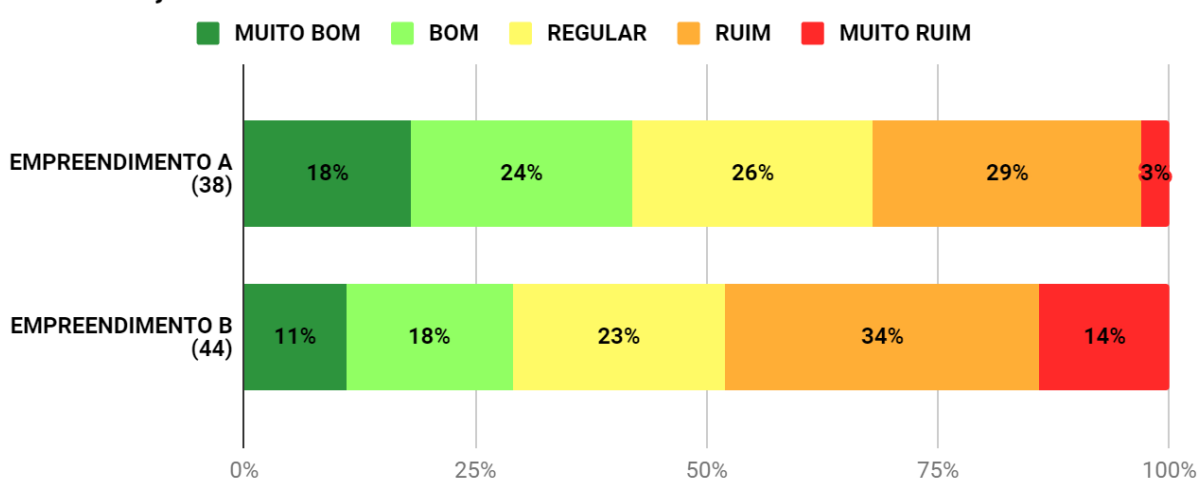

Figura 23 - Gráfico da facilidade de mobiliar a cozinha

\section{FACILIDADE DE MOBILIAR DA COZINHA}

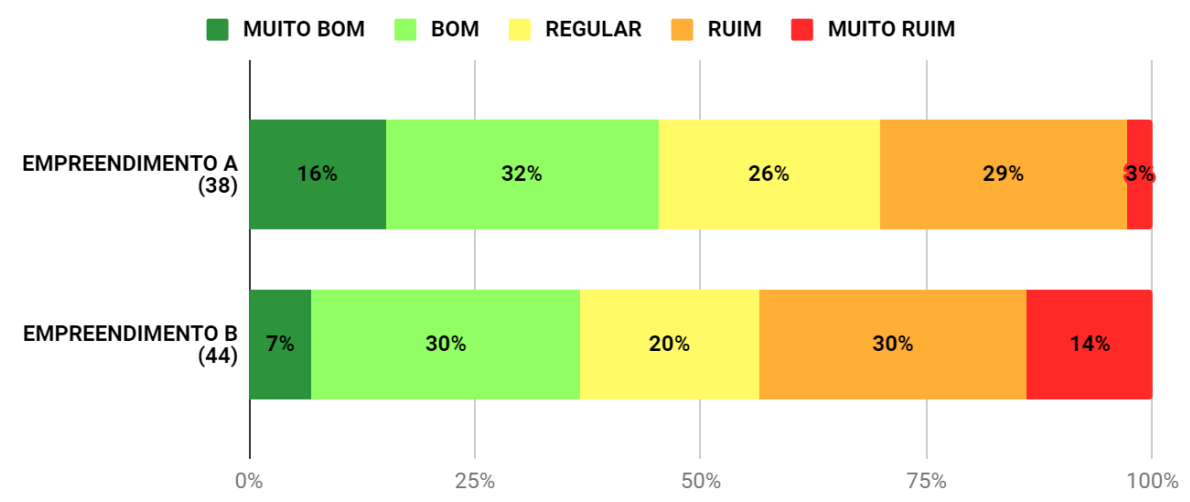

Figura 24 - Cozinha e fundos originais do empreendimento B

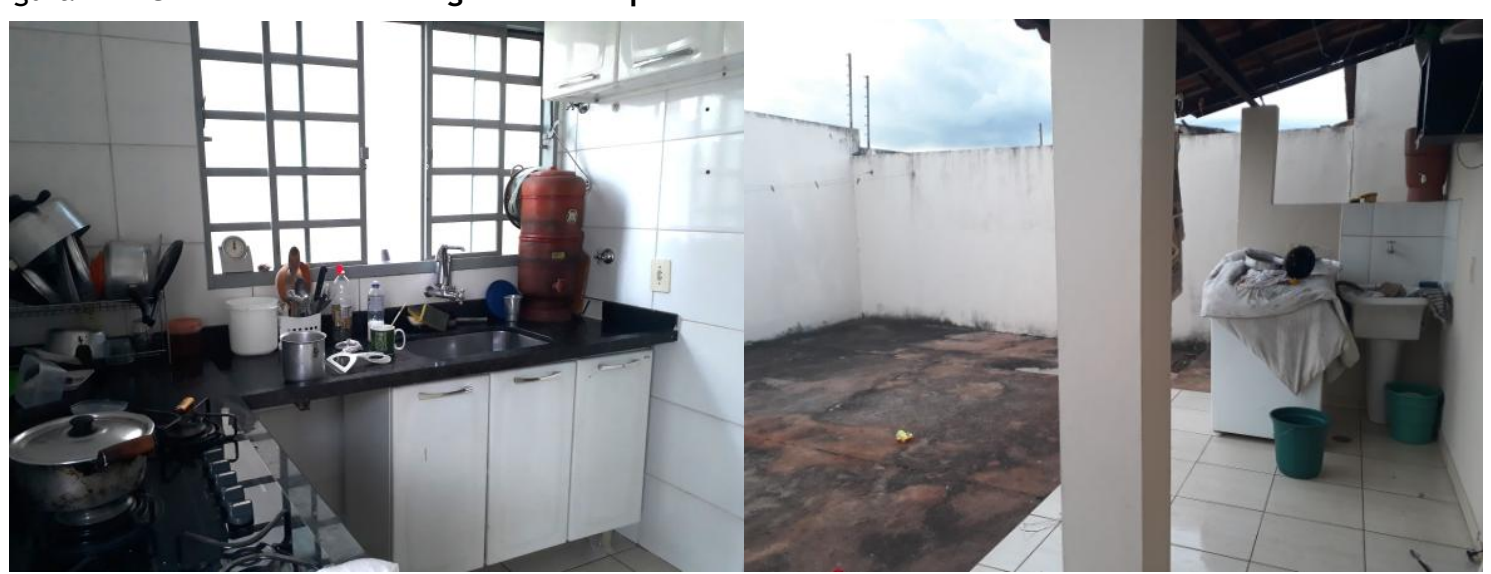


Figura 25 - Exemplos de fundo reformado: à esquerda uma cozinha e à direita usado como cozinha e área de serviços

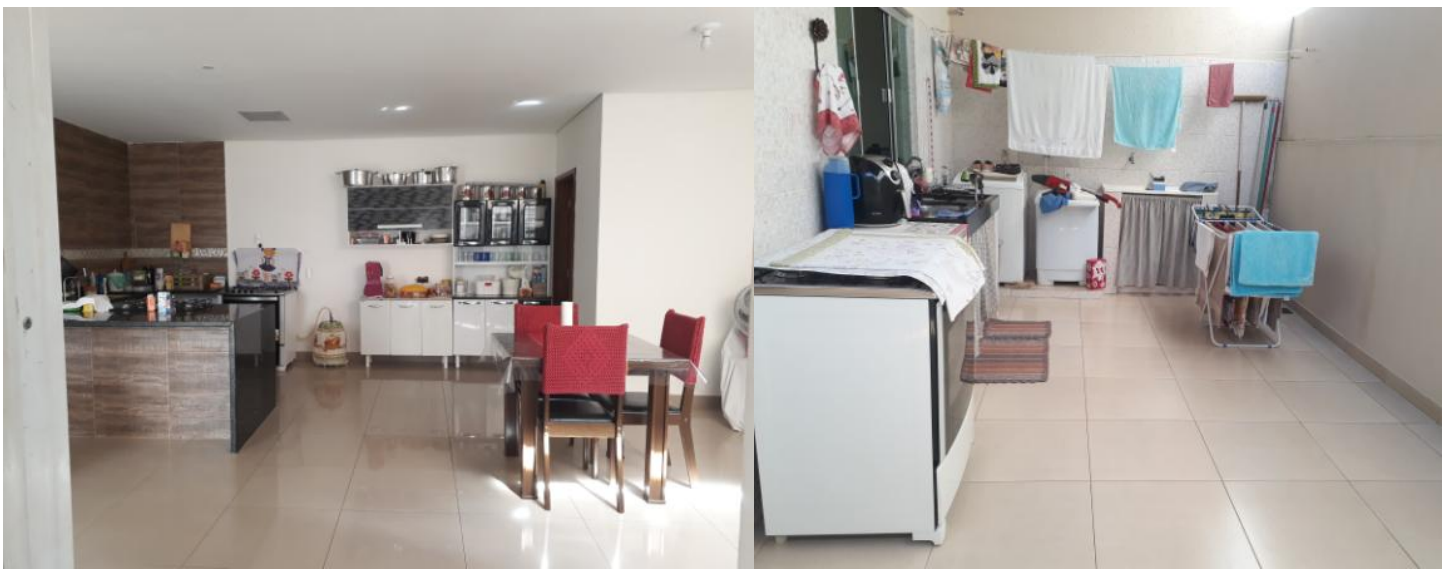

Figura 26 - Cozinha sem uso, à esquerda, e cozinha nova acrescentada nos fundos, à direita

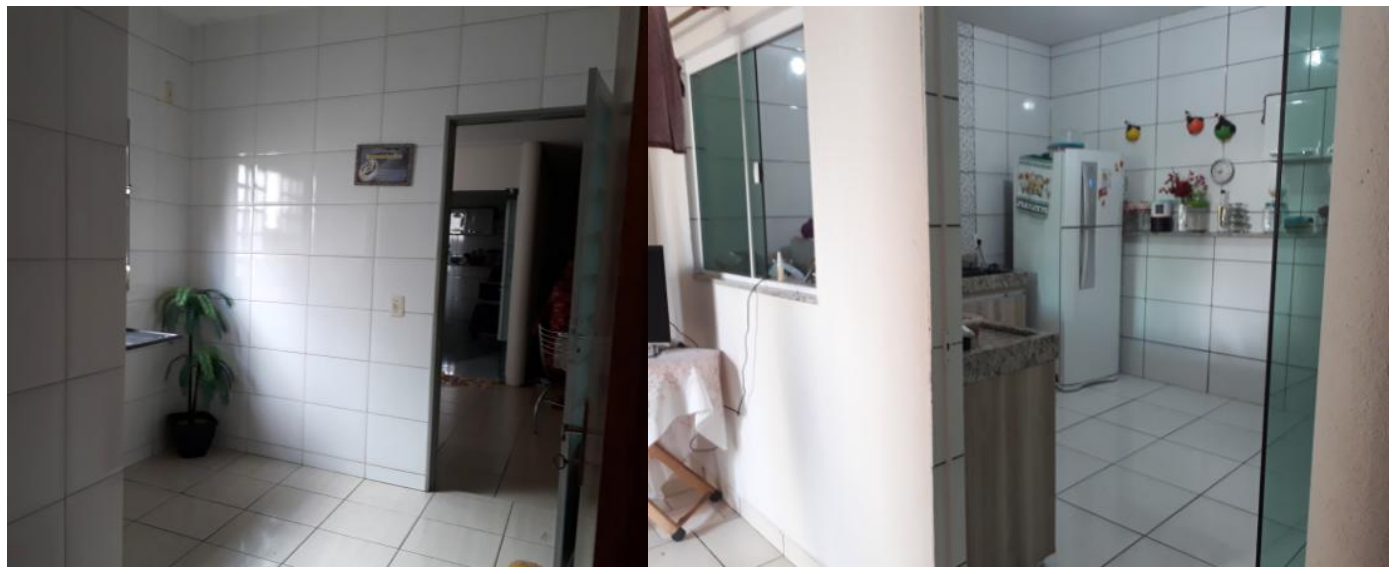

Outra análise a ser realizada diz respeito à relação entre o tamanho dos ambientes e a sobreposição de usos que ocorrem neles. Através do uso do aplicativo foi possível gerar uma análise percentual de todas as atividades realizadas em cada cômodo, demonstrando mais uma forma de gráfico que possibilita diferentes análises por meio dele. O gráfico da Figura 27 demonstra, no caso do empreendimento B, que o cômodo da cozinha possui uma variedade de atividades realizadas nesse local. Isso se deve ao fato de que a área ampliável nos fundos da casa no empreendimento B, indicada na Figura 19, permite a criação de cômodos maiores, o que gera espaço suficiente para a realização de diversas atividades, antes realizadas com desconforto nos ambientes da casa original.

Também é possível constatar uma variedade de atividades realizadas na sala de estar, em ambos os empreendimentos (Figuras 28 a 30), fato que se deve por esse ser o maior ambiente da unidade, nos dois casos. Por esse motivo, na sala de estar se realizam atividades distintas das convencionais, demonstrando a falta de espaço para o desempenho dessas atividades nos ambientes apropriados. Ao analisar o gráfico da Figura 28, é possível perceber que na sala de estar atividades como passar roupa e fazer refeições são realizadas nesse ambiente.

Em relação à seção "Hábitos sustentáveis", presente no aplicativo, alguns aspectos relacionados à consciência ambiental podem ser associados à diferença entre o grau de escolaridade dos dois empreendimentos, já indicado no gráfico correspondente à Figura 10. Nota-se uma discrepância entre a satisfação com a quantidade de áreas verdes nos dois condomínios (Figura 31), uma vez que a maioria dos moradores do grupo A considera ruim essa quantidade, enquanto do grupo B considera regular ou até mesmo muito boa, o que aponta um fato crítico, visto que uma análise arquitetônica indica que a quantidade de áreas verdes nesse empreendimento é mínima (Figura 32). Além disso, a ferramenta comprovou que a possibilidade de ter um jardim nos fundos da casa, com uma área livre verde disponível, gera sensação de

240 Villa, S. B.; Bruno, D. C.; Santos, A. L. T. dos 
maior quantidade de áreas verdes em quem mora nas casas, o que pode ter gerado uma confusão entre espaço público e privado.

Figura 27 - Atividades realizadas na cozinha

\section{ATIVIDADES REALIZADAS NA COZINHA}

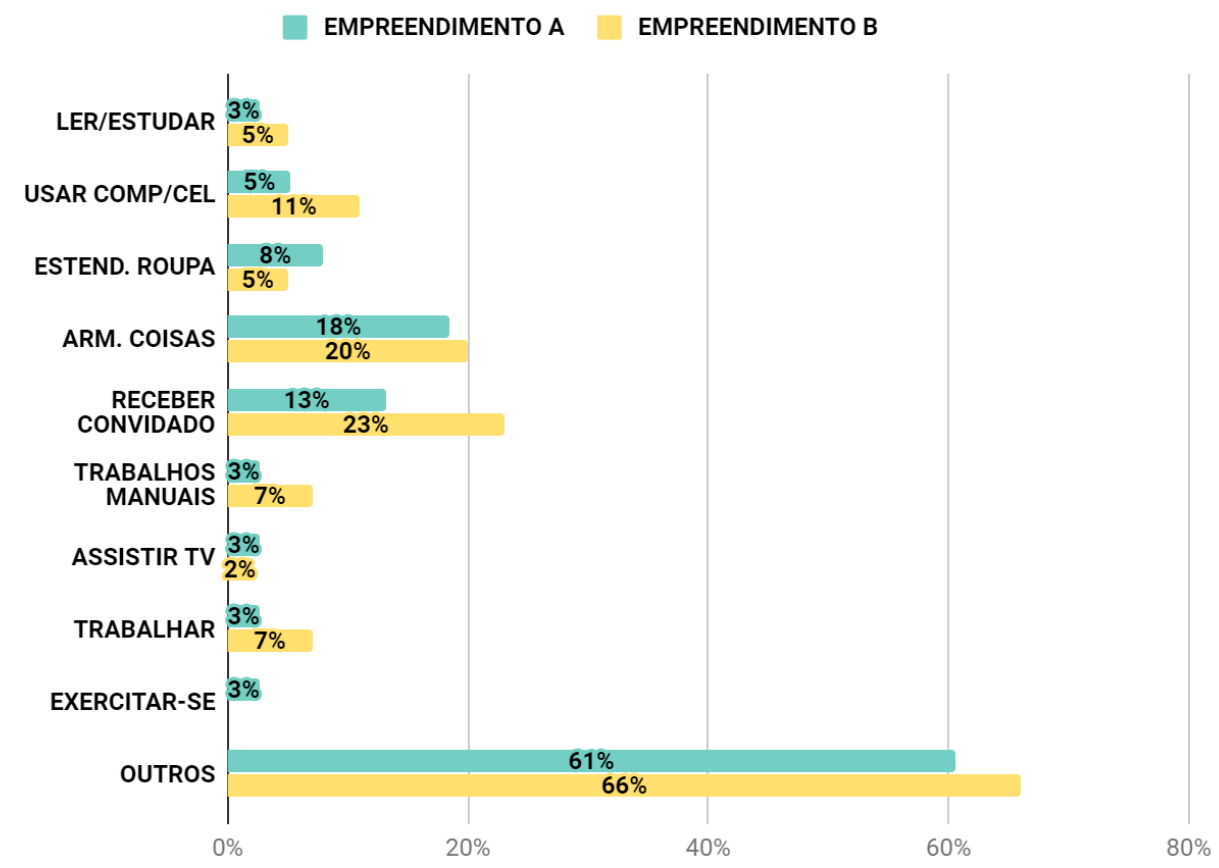

Figura 28 - Atividades realizadas na sala de estar

ATIVIDADES REALIZADAS NA SALA DE ESTAR

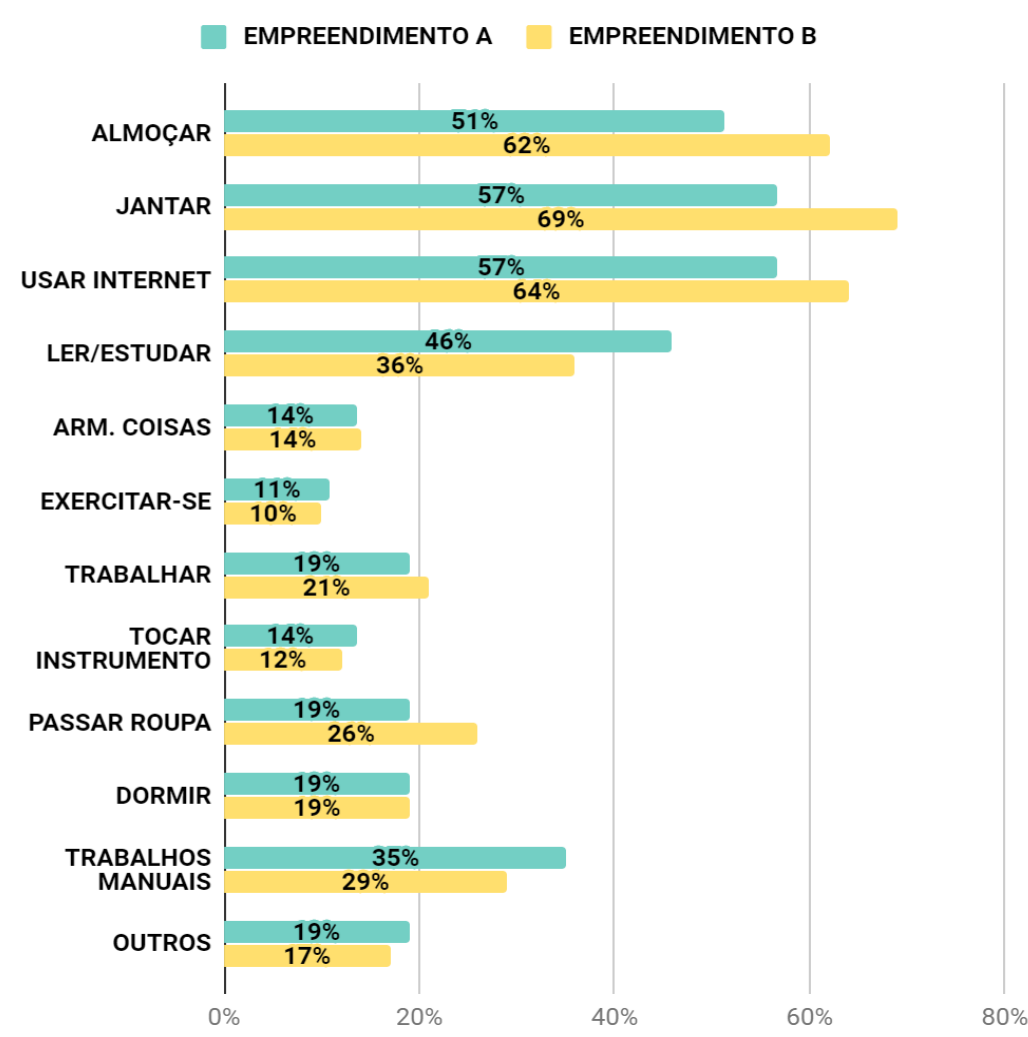


Figura 29 - Atividades realizadas na sala e cozinha no empreendimento A

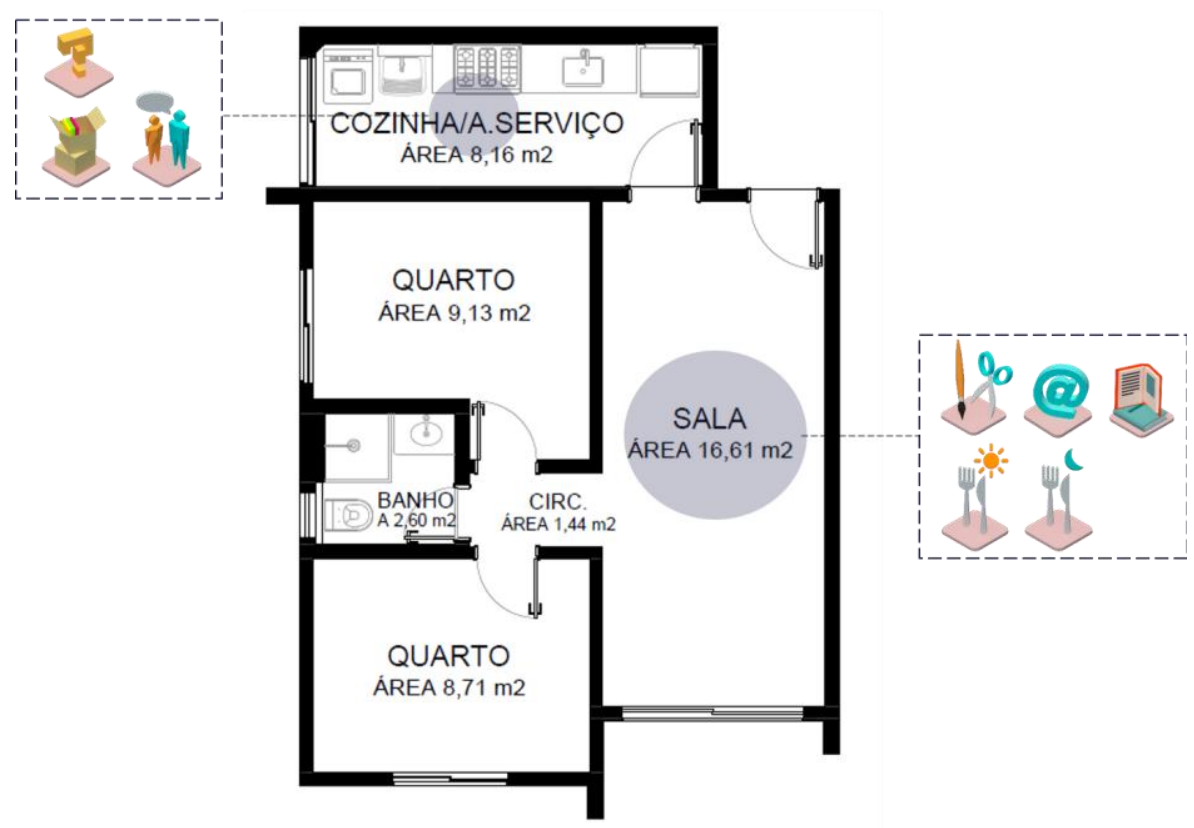

Figura 30 - Atividades realizadas na sala e cozinha no empreendimento $B$

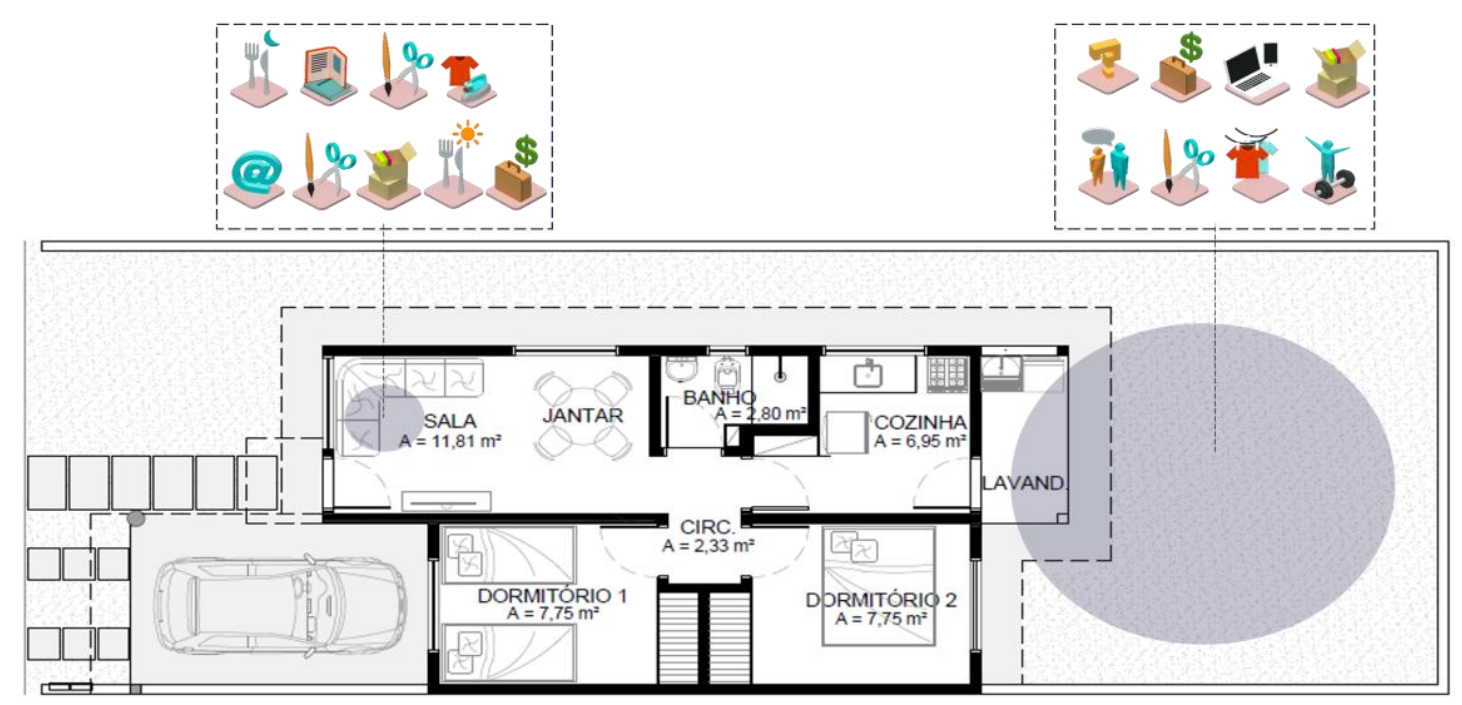

Figura 31 - Gráfico da satisfação com relação à quantidade de áreas verdes no condomínio SATISFAÇÃO QUANTIDADE DE ÁREAS VERDES

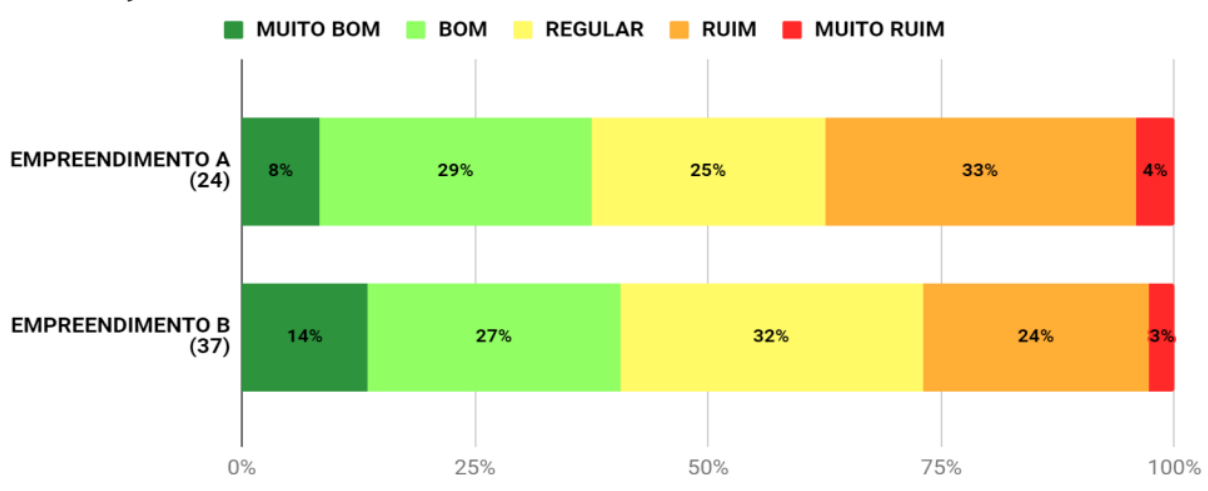


Figura 32 - Área verde nos fundos do empreendimento B

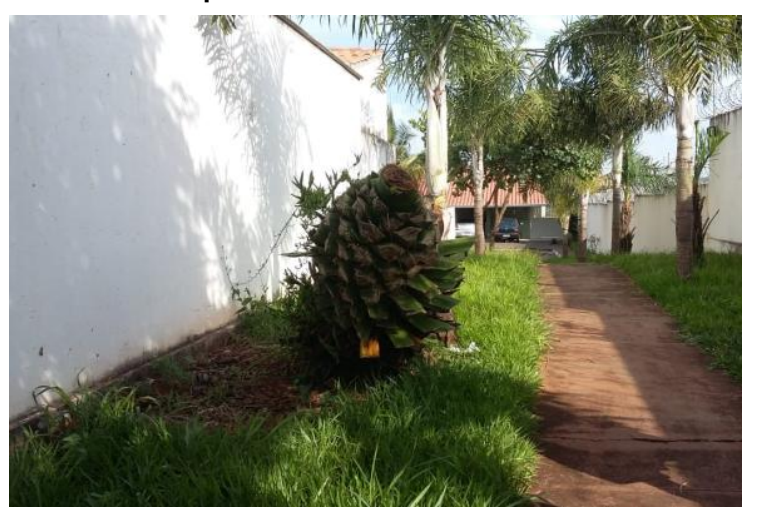

Ao se tratar de questões como a separação do lixo reciclável, no empreendimento B, 52\% dos moradores separam o lixo, e no empreendimento A esse número chega a 74\% (Figura 33). Apesar disso, a maioria dos entrevistados não sabe o destino desse lixo reciclável, ou se existem ecopontos próximos ao seu bairro, o que demonstra que muitas vezes esse lixo é separado, mas não é bem descartado. Nesse sentido, a falta de consciência ambiental por parte dos moradores fica evidente. A porcentagem de moradores do empreendimento B que separa o lixo reciclável é menor em relação ao empreendimento A, como apontado anteriormente. Nesse empreendimento há uma lixeira com separação para cada tipo de lixo, e catadores que recolhem esse lixo. Mesmo assim, alguns moradores acham difícil separar ou argumentam que não existe coleta seletiva no bairro.

Em relação ao consumo de alimentos orgânicos, pode-se constatar que tal prática ainda está em processo de consolidação entre os moradores entrevistados, visto que $36 \%$ dos moradores do empreendimento A e apenas $16 \%$ do empreendimento B a realizam (Figura 34). A falta de conhecimento sobre esse tipo de alimentação fica evidente quando observados os tipos de alimentos orgânicos consumidos, sendo a maior porcentagem restringida ao consumo de frutas e verduras, enquanto os produtos de origem animal apresentaram baixíssima expressividade (Figura 35). Além disso, o motivo principal para tal consumo é a preocupação com a saúde (Figura 36) e não pensando em evitar danos ao meio ambiente (5\% no empreendimento A e $9 \%$ no empreendimento B). Assim, ressalta-se a necessidade de incentivos públicos aos produtores que utilizam formas alternativas de cultivo, visando aumentar a oferta e o acesso aos alimentos orgânicos.

A partir das respostas advindas do aplicativo/questionário e armazenadas no banco de dados do sistema, foi possível gerar gráficos relativos aos diferentes aspectos avaliados, permitindo a comparação entre os diversos perfis de moradores e sua satisfação em relação à moradia em que vivem. Dessa forma, os resultados apresentados se referem à análise dos dados quantitativos relativos à qualidade das habitações. Foram expostos com o objetivo de exemplificar uma das maneiras com a qual o aplicativo/questionário interativo pode ser utilizado, bem como os tipos de dados e sua forma de organização em gráficos e respectivas análises.

\section{Conclusão}

\section{Aspectos referentes ao método}

O questionário/aplicativo "Como você mora?", como ferramenta para APO, possibilita retroalimentar projetos futuros, além de fornecer informações estatísticas e científicas que auxiliam na realização de projetos com maior qualidade ambiental, bem como contribuir para a implementação de políticas públicas relacionadas à sustentabilidade. Apresenta também grande potencial em relação a novos formatos de avaliação pós-ocupação, utilizando ferramentas digitais e um banco de dados integrado. A interface interativa do aplicativo CVM, juntamente com seu design convidativo e lúdico, facilita a compreensão do usuário e a transferência de conhecimento, atingindo uma quantidade maior de pessoas, as quais se interessam mais por essa interface em relação aos questionários tradicionais, realizados em papel, diversificando as informações colhidas. Assim, o questionário/aplicativo CVM pode impactar direta e positivamente na área de "Pesquisa em habitação", sendo possível atingir um alcance global, através de sua interface interativa e disponibilização para download, diretamente no Google Play. Além disso, o projeto 
possui como intenção futura a disponibilização dos resultados aos usuários, através dos gráficos, buscando responder à pergunta instigada pelo aplicativo "Como você mora?". Para isso, o morador teria acesso direto aos gráficos, por meio de uma plataforma Web, sendo possível observar sua condição em relação ao restante dos respondentes. O intuito é de que o aplicativo, juntamente com o Sistema APO Digital, possam ser replicados em pesquisas futuras, podendo ser um canal aberto à comunidade. Por meio do uso da ferramenta na aplicação do questionário, foi possível constatar que um sistema interativo em meios digitais, além de aumentar a eficiência dos resultados de uma APO, também desperta maior interesse no usuário, no sentido de proporcionar uma experiência mais positiva e lúdica, suprindo assim as deficiências das avaliações pósocupação em moradias feitas em questionários em papel.

Figura 33 - Separação entre o lixo reciclável e comum

VOCÊ SEPARA O LIXO ENTRE RECICLÁVEL E COMUM?

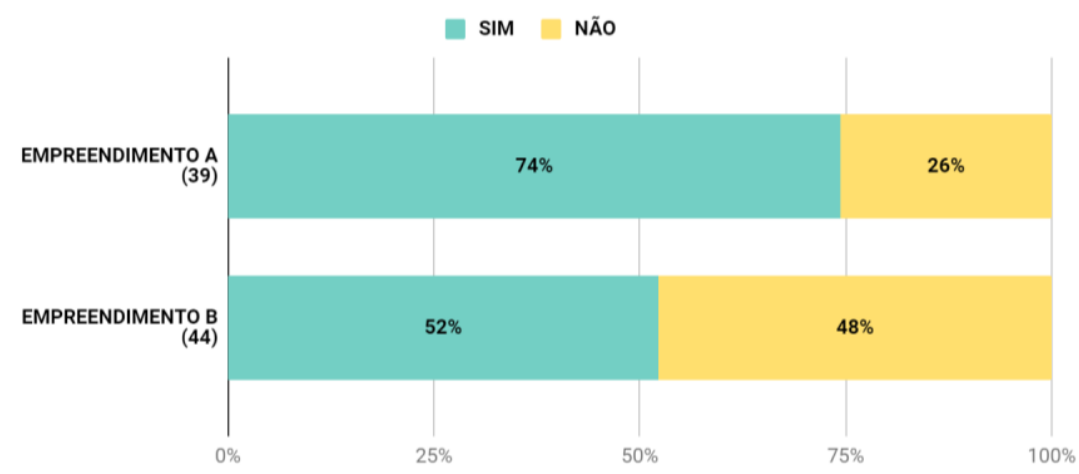

Figura 34 - Gráfico do consumo de alimentos orgânicos

VOCÊ CONSOME ALIMENTOS ORGÂNICOS?

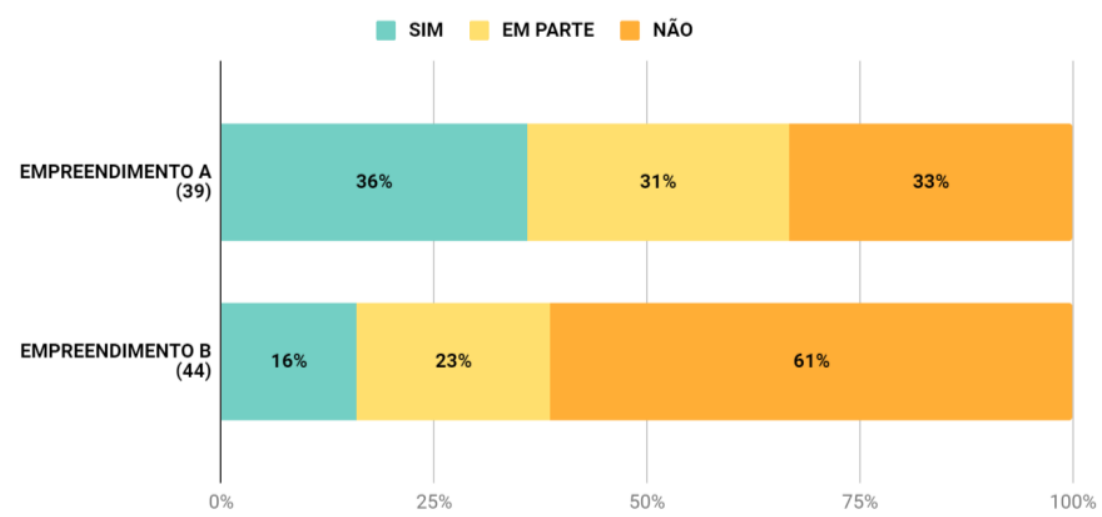

Figura 35 - Gráfico do tipo de alimentos orgânicos consumidos

QUAIS TIPOS DE ALIMENTO ORGÂNICO VOCÊ CONSOME?

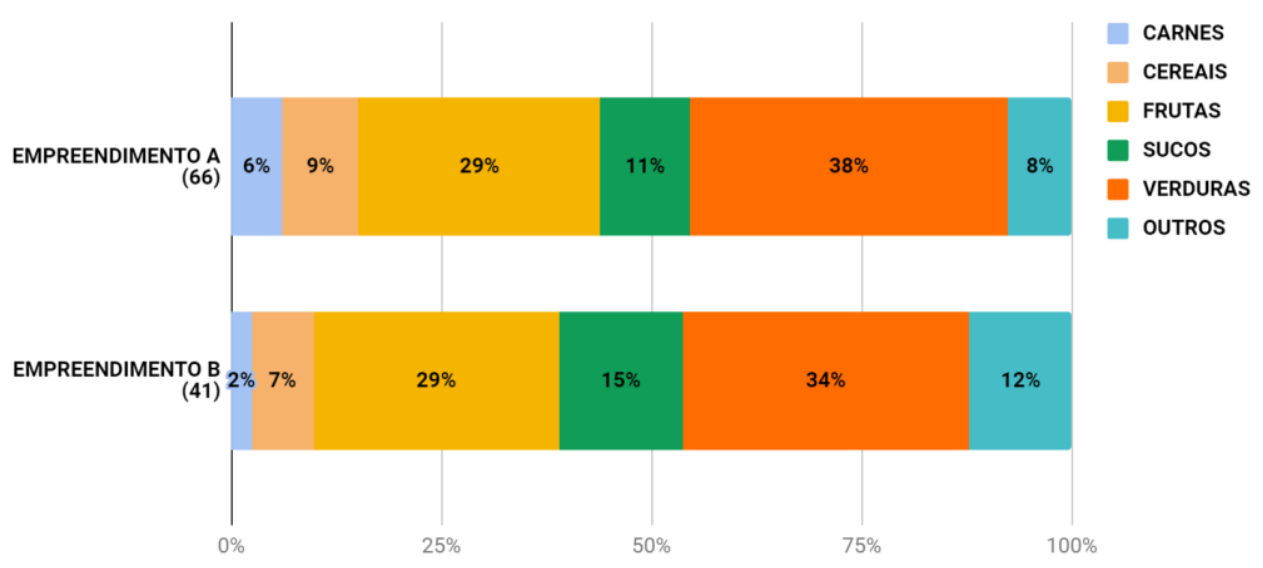


Figura 36 - Gráfico do tipo de alimentos orgânicos consumidos

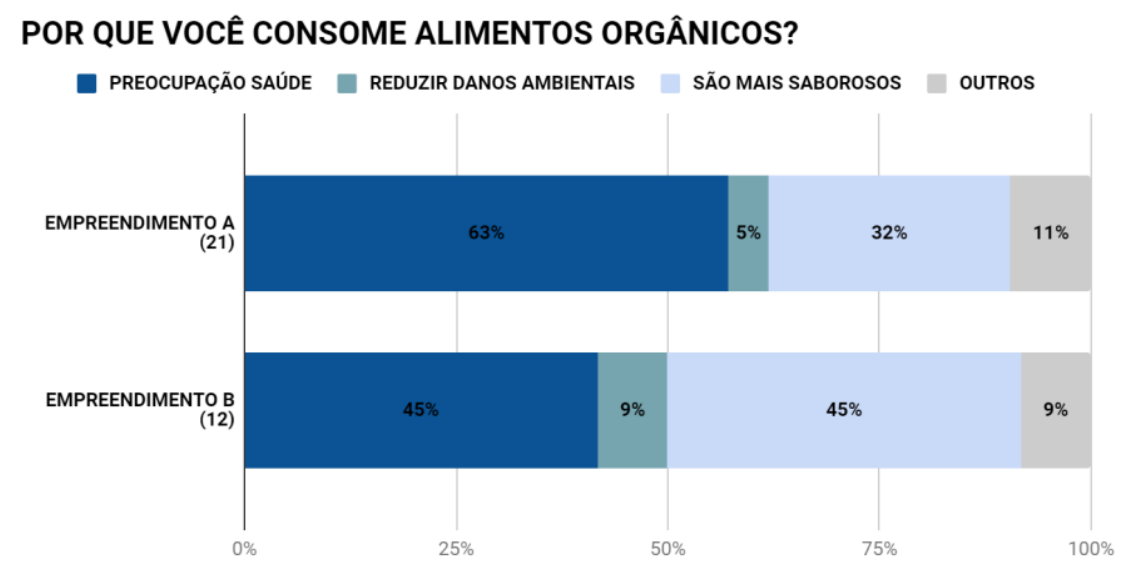

\section{Aspectos referentes ao estudo de caso}

A partir da aplicação e da posterior geração de gráficos através do banco de dados (Sistema APO Digital), foi possível realizar uma análise crítica dos resultados obtidos e posterior comparação entre os empreendimentos escolhidos, no intuito de identificar as qualidades e problemáticas encontradas neles, visando melhorar a qualidade das habitações em projetos futuros. Foram detectados problemas já observados frequentemente em pesquisas semelhantes, principalmente ao se tratar de habitações de interesse social. Podem ser elencadas questões relativas à repetição das mesmas tipologias tripartidas, oferecidas a diferentes perfis familiares, com diferentes demandas; insuficiência dos espaços para comportar as atividades dos moradores, mesmo as essenciais; baixa qualidade construtiva; insuficiência e baixa qualidade dos equipamentos de uso coletivo dos condomínios; forma como as unidades habitacionais estão inseridas na cidade e se relacionam com o espaço urbano; e falta de serviços e equipamentos próximos à moradia. Através do Sistema APO Digital, os resultados obtidos, referentes à qualidade das habitações avaliadas, podem ser acessados por entidades e setores governamentais, industriais e civis, contribuindo assim para a melhora da qualidade das habitações, a partir da observação e análise de problemáticas como as citadas na presente pesquisa, aliado a ações e propostas de melhoria para os projetos de unidades e conjuntos habitacionais. Outra problemática identificada se relaciona com o baixo grau de consciência ambiental, que também pode apresentar melhorias, através do uso do questionário interativo e do Sistema APO Digital. O aplicativo, por possuir uma seção educativa acerca da prática de hábitos sustentáveis, pode contribuir para a implementação de políticas públicas relacionadas à sustentabilidade, além de oferecer feedbacks que informam os respondentes quanto a ações que possam gerar maior impacto ambiental. Futuramente poderão ser implementadas no CVM outras funcionalidades, no sentido de fortalecer ainda mais as conexões entre as comunidades acadêmicas, civis e governamentais.

\section{Referências}

AMBROSE, G.; HARRIS, P. Layout. Porto Alegre: Bookman, 2012.

AMORE, C. S.; SHIMBO, L. Z.; RUFINO, M. B. (org). Avaliação do Programa Minha Casa Minha Vida em seis estados brasileiros. Rio de Janeiro: Letra Capital, 2015.

ASSOCIAÇÃO BRASILEIRA DE NORMAS TÉCNICAS. NBR 15575: norma de desempenho de edificações. Rio de Janeiro, 2013.

BAKER, N.; STEEMERS, K. Healthy homes: designing with light and air for sustainability and wellbeing. London: RIBA, 2019.

CAIXA. Cartilha Caixa Minha Casa Minha Vida. 2009. Disponível em:

https://www.ademi.org.br/docs/CartilhaCaixa.pdf. Acesso em: 25 de jan. 2019.

COLE, R. J. Building environmental assessment methods: redefining intentions and roles. Building Research \& Information, v. 33, n. 5, p. 455-467, fev. 2007. 
MELLORY-HILL, S.; PREISER, W.F. E.; WATSON, C.G. (org.). Enhancing building performance. Oxford: Wiley-Blackwell, 2012.

ONO, R. et al. (org.). Avaliação Pós-Ocupação (APO) na Arquitetura, no Urbanismo e no Design: da teoria à prática. São Paulo: Oficina de Textos, 2018.

PREECE, J.; ROGERS, Y.; SHARP, H. Design de interação: além da interação homem-computador. São Paulo: Bookman, 2005.

PREISER, W.F.E.; VISCHER, J. C. (ed.). Assessing building performance. Oxford:ElsevierButterworthHeinemann, 2005.

SANTAELLA, L. Matrizes da linguagem e pensamento: sonora, visual, verbal: aplicações na hipermídia. 3. ed. São Paulo: Iluminuras: FAPESP, 2005.

SARAMAGO, R. C. P.; VILLA, S. B.; SILVA, A. C. Como você mora: avaliação da qualidade ambiental de habitações. In:ENCONTRO NACIONAL, 9,; ENCONTRO LATINO-AMERICANO, 7.; ENCONTRO LATINO-AMERICANO E EUROPEU SOBRE EDIFICAÇÕES E COMUNIDADES SUSTENTÁVEIS, 2.; São Leopoldo, 2017.Anais [...] São Leopoldo, 2017.

STEVENSON, F. Housing fit for purpose: performance, feedback and learning. London: RIBA, 2019.

STEVENSON, F.; BABORSKA-NAROZNY, M.Housing performance evaluation: challenges for international knowledge exchange. Building Research \& Information, v. 46, n. 5, p. 501-512, 2018.

STEVENSON, F.; LEAMAN, A. Evaluating housing performance in relation to human behaviour: new challenges. BuildingResearch\&Information, v. 38, n. 5, p.437-44, 2010.

UBERLÂNDIA. Lei Complementar no 524, de 08 de abril de 2011, que institui o código municipal de obras do município de Uberlândia e de seus distritos. Uberlândia, 2011. Disponível em: http://www.uberlandia.mg.gov.br/uploads/cms_b_arquivos/120.pdf. Acesso em: jan. 2019.

UNGER, R.; CHANDLER, C. O guia para projetar UX: a experiência do usuário (ux) para projetistas de conteúdo digital, aplicações e web sites. Rio de Janeiro: Alta Books Editora. 2009.

VAN DER VOORDT, T. J. M.; VAN WEGEN, H. B. R. Arquitetura sob o olhar do usuário. São Paulo: Oficina de Textos, 2013.

VILLA, S. B. Morar em Apartamentos: a produção dos espaços privados e semi-privados nos apartamentos ofertados pelo mercado imobiliário no século XXI em São Paulo e seus impactos na cidade de Ribeirão Preto. Critérios para Avaliação Pós-Ocupação.São Paulo, 2008. Tese (Doutorado em Arquitetura e Urbanismo) - Faculdade de Arquitetura e Urbanismo, Universidade de São Paulo, São Paulo, 2008.

VILLA, S. B.; ORNSTEIN, S. W. (org.). Qualidade ambiental na habitação: avaliação pós-ocupação. São Paulo: Oficina de Textos, 2013.

VILLA, S. B.; SARAMAGO, R. C. P.; GARCIA, L. C. Avaliação pós-ocupação no programa Minha Casa Minha Vida: uma experiência metodológica. Uberlândia: Universidade Federal de Uberlândia, 2015. Disponível em: https://morahabitacao.files.wordpress.com/2015/07/os-014631-proex-ufu-livro-sangrialu.pdf. Acesso em: 8 mai. 2020.

YIN, R. K. Estudo de caso: planejamento e métodos.4. ed. Porto Alegre: Bookman, 2010.

ZANDONÁ, D. Testes de usabilidade. 2017. Disponível em: https://pt.slideshare.net/DanieleZ/testes-deusabilidade-77273046. Acesso em: 15 set. 2018.

\section{Agradecimentos}

Agradecemos ao CNPq, Capes, Fapemig e à UFU pelo apoio à pesquisa. 


\section{Simone Barbosa Villa}

Programa de Pós-Graduação em Arquitetura e Urbanismo | Universidade Federal de Uberlândia | Av. João Naves de Ávila, 2121, Bloco 1I, Sala 236 | Uberlândia - MG- Brasil | CEP 38408-100 | Tel.: (34) 99678-6970 | E-mail: simonevilla@ufu.br

\section{Dominique Cunha Bruno}

Faculdade de Arquitetura e Urbanismo e Design | Universidade Federal de Uberlândia | Tel.: (34)99792-3662 | Email:dominiquecunha28@gmail.com

\section{Ana Luísa Trevisan dos Santos}

Faculdade de Arquitetura e Urbanismo e Design | Universidade Federal de Uberlândia | Tel.: (16)9996-14461 | E-mail: ana.luisats@outlook.com

\section{Ambiente Construído}

Revista da Associação Nacional de Tecnologia do Ambiente Construído

Av. Osvaldo Aranha, $99-3^{\circ}$ andar, Centro

Porto Alegre - RS - Brasil

$$
\text { CEP } 90035-190
$$

Telefone: +55 (51) 3308-4084

Fax: +55 (51) 3308-4054

www.seer.ufrgs.br/ambienteconstruido

E-mail: ambienteconstruido@ufrgs.br

This is an open-access article distributed under the terms of the Creative Commons Attribution License. 